Supplement of Hydrol. Earth Syst. Sci., 22, 6591-6609, 2018

https://doi.org/10.5194/hess-22-6591-2018-supplement

(C) Author(s) 2018. This work is distributed under

the Creative Commons Attribution 4.0 License.

(c) (1)

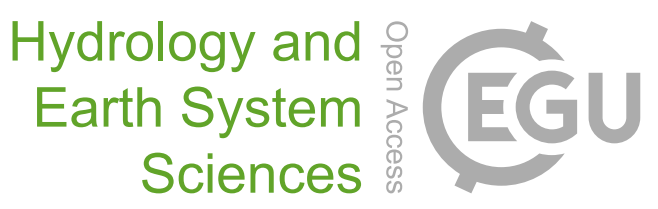

Supplement of

\title{
On the skill of raw and post-processed ensemble seasonal meteorological forecasts in Denmark
}

Diana Lucatero et al.

Correspondence to: Diana Lucatero (diana.lucatero@ign.ku.dk)

The copyright of individual parts of the supplement might differ from the CC BY 4.0 License. 
Precipitation
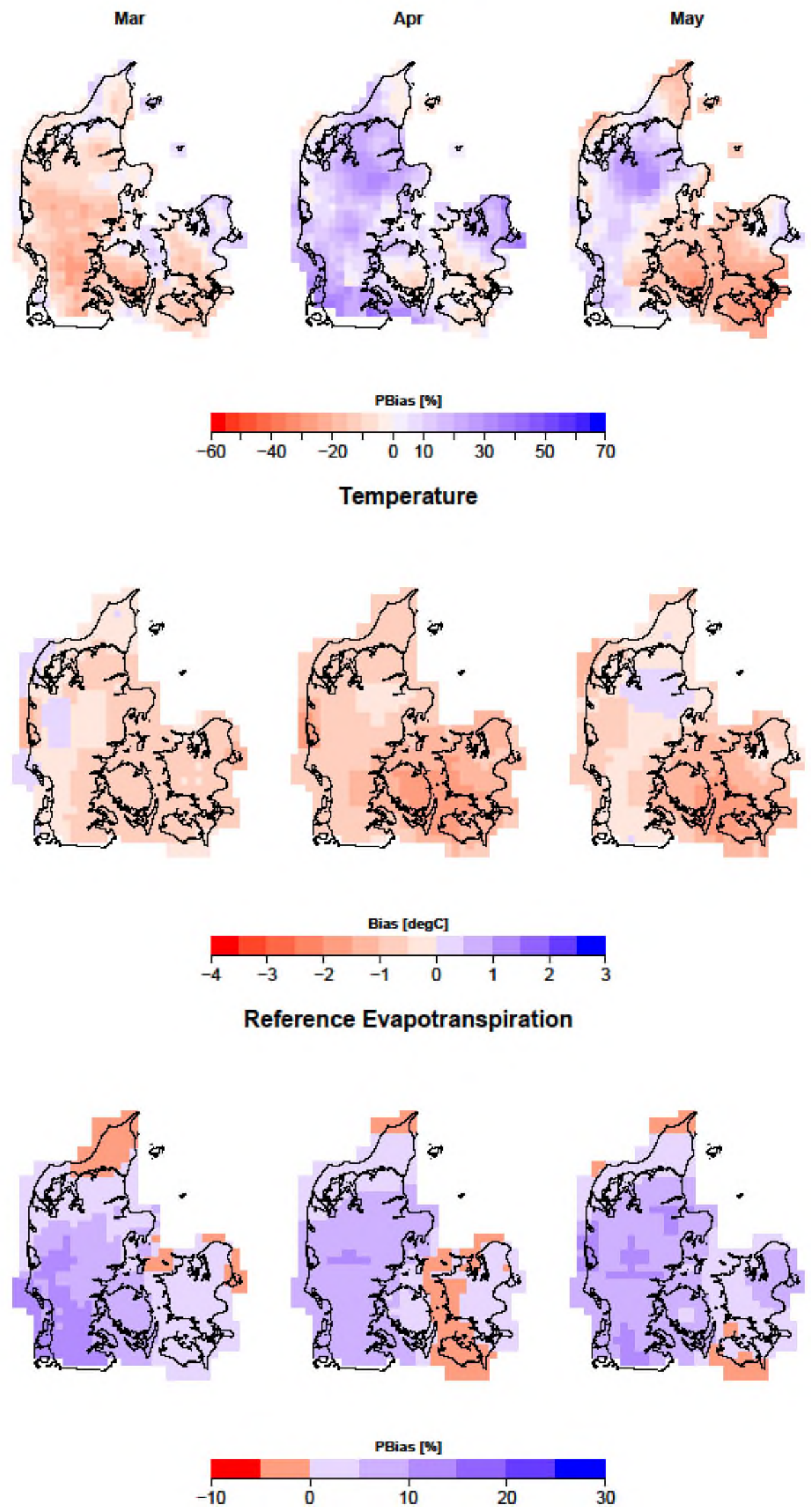
Figure S1: As in Fig. 4, but for spring. 


\section{Precipitation}
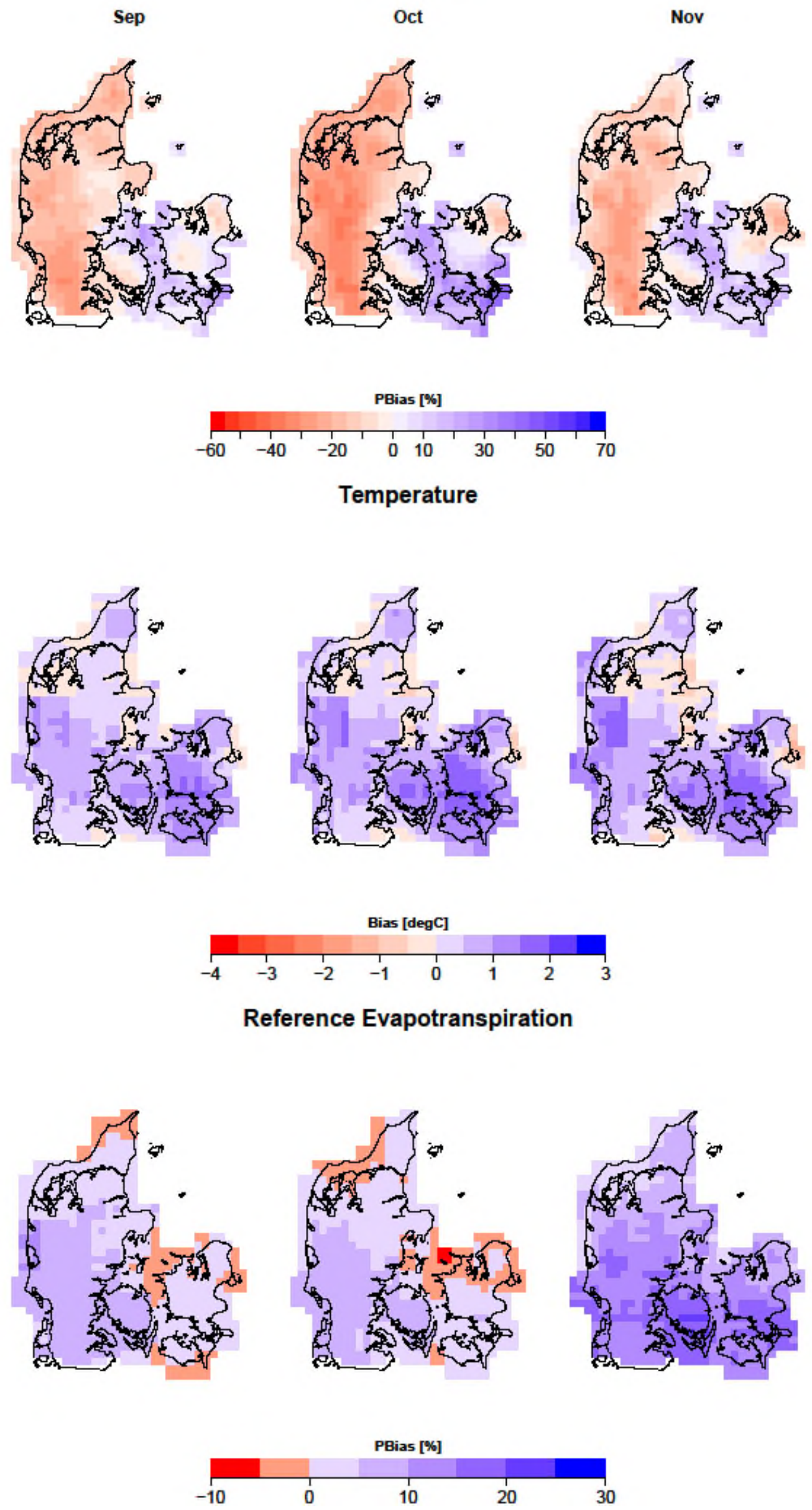
Figure S2: As in Fig. 4, but for autumn. 


\section{Precipitation}
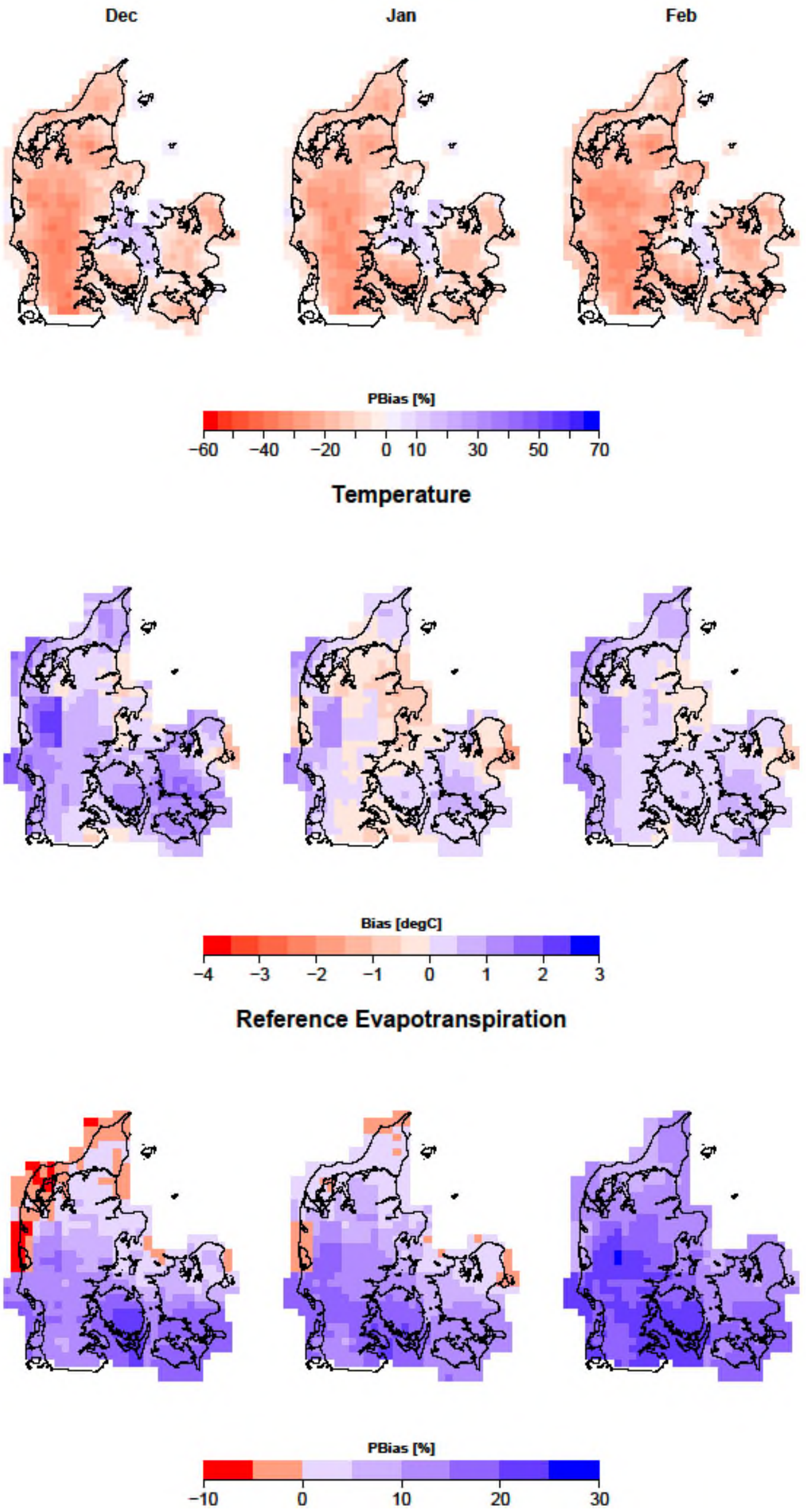
Figure S3: As in Fig. 4, but for winter. 


\section{Precipitation}
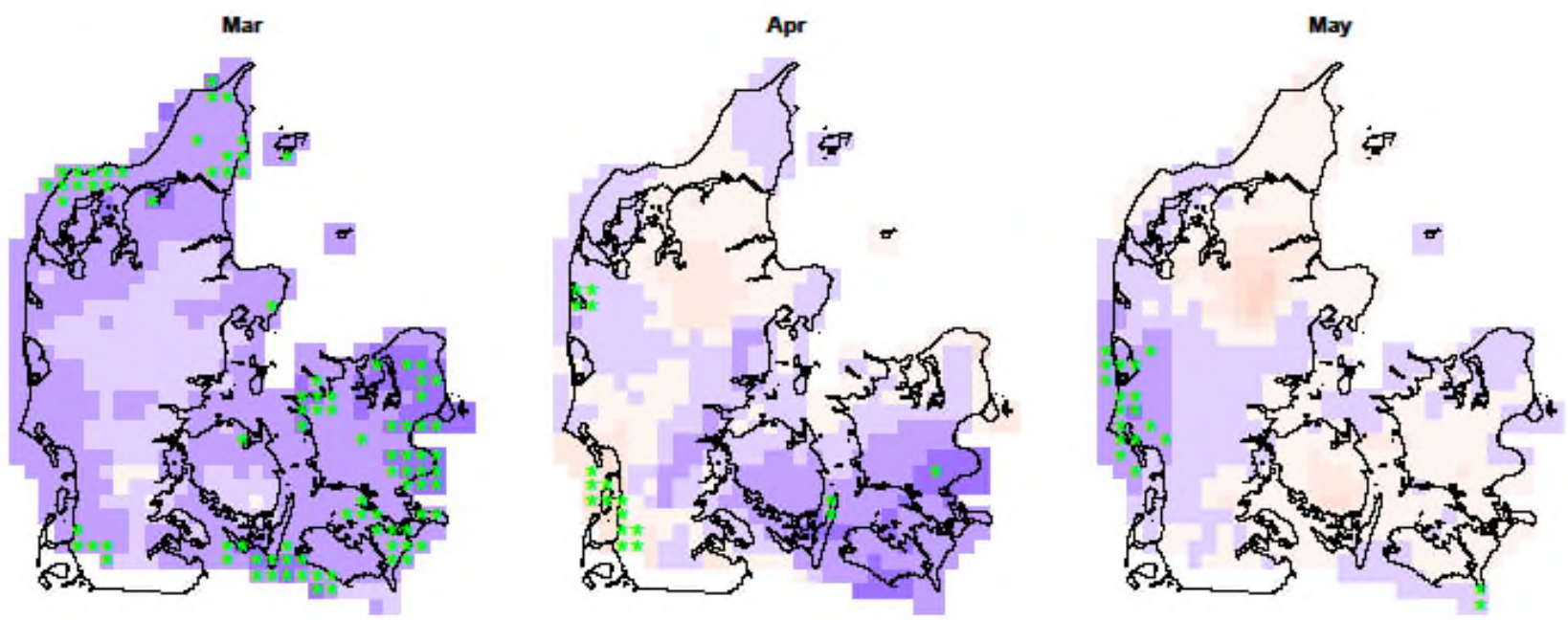

Temperature
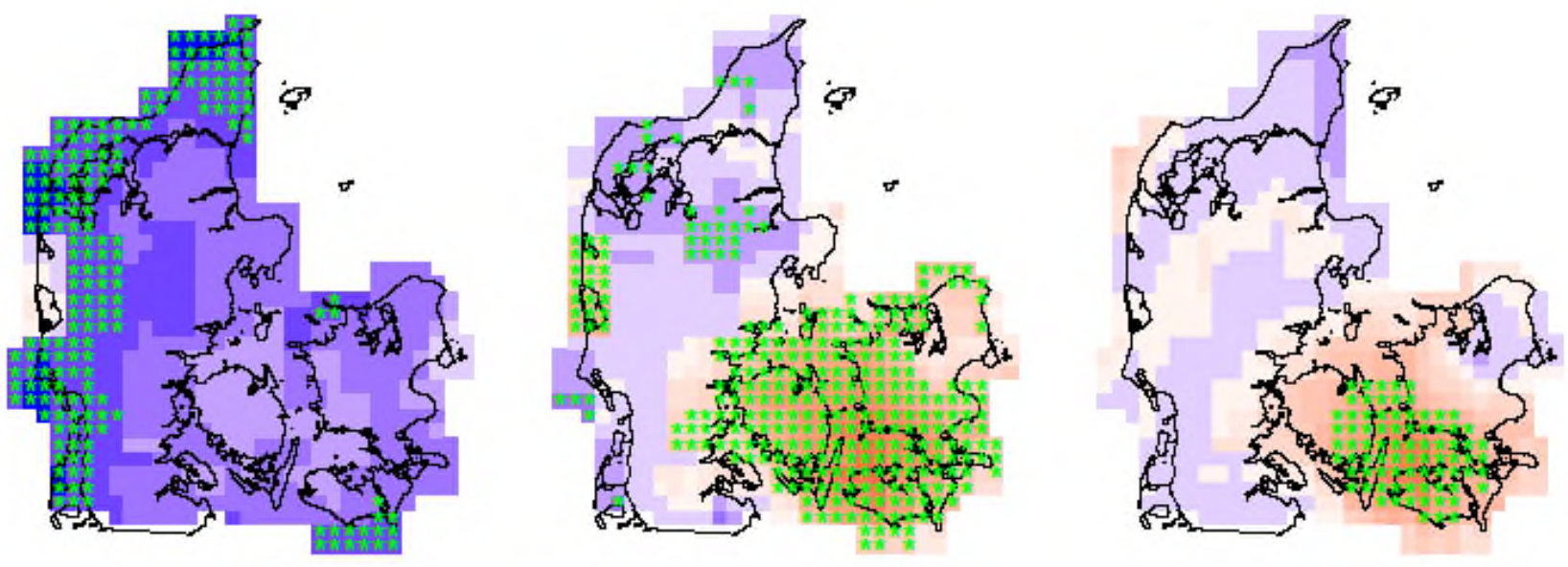

Reference Evapotranspiration
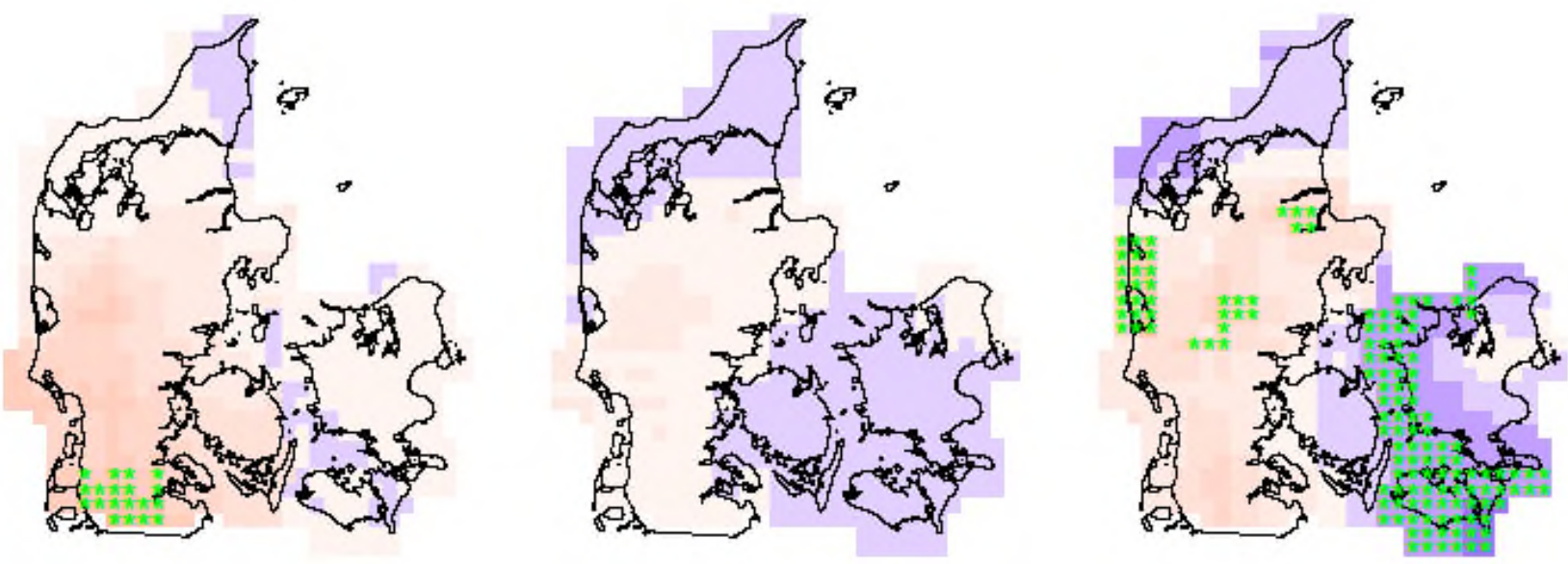

CRPSS

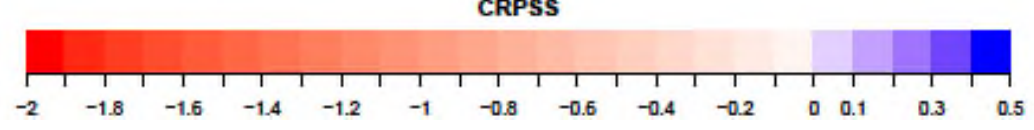


Figure S4: As in Fig. 6, but for spring. 


\section{Precipitation}
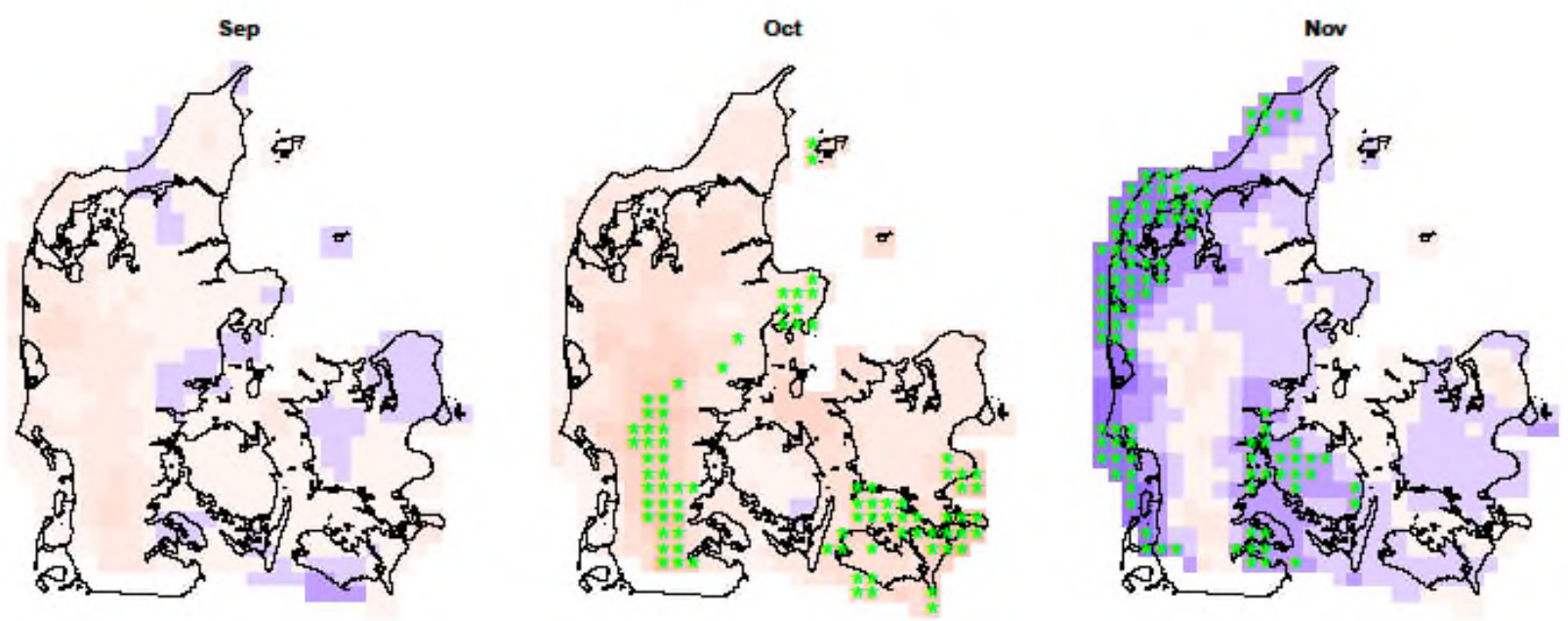

\section{Temperature}
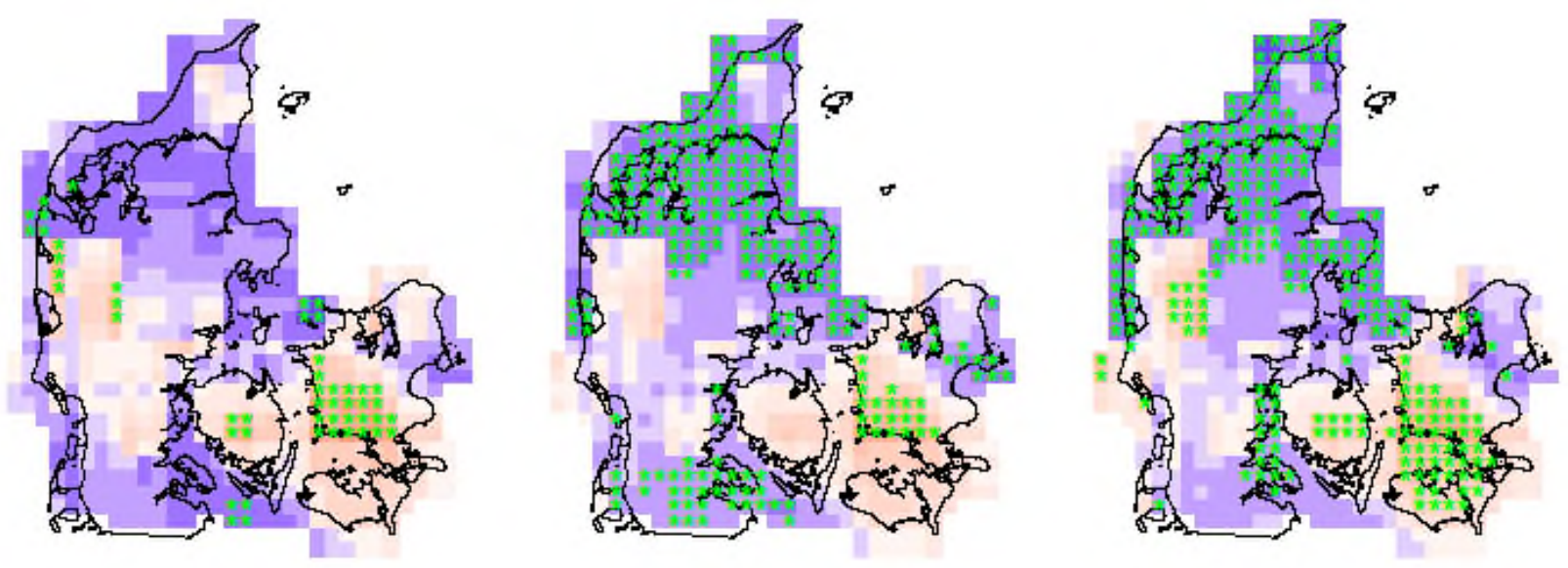

Reference Evapotranspiration
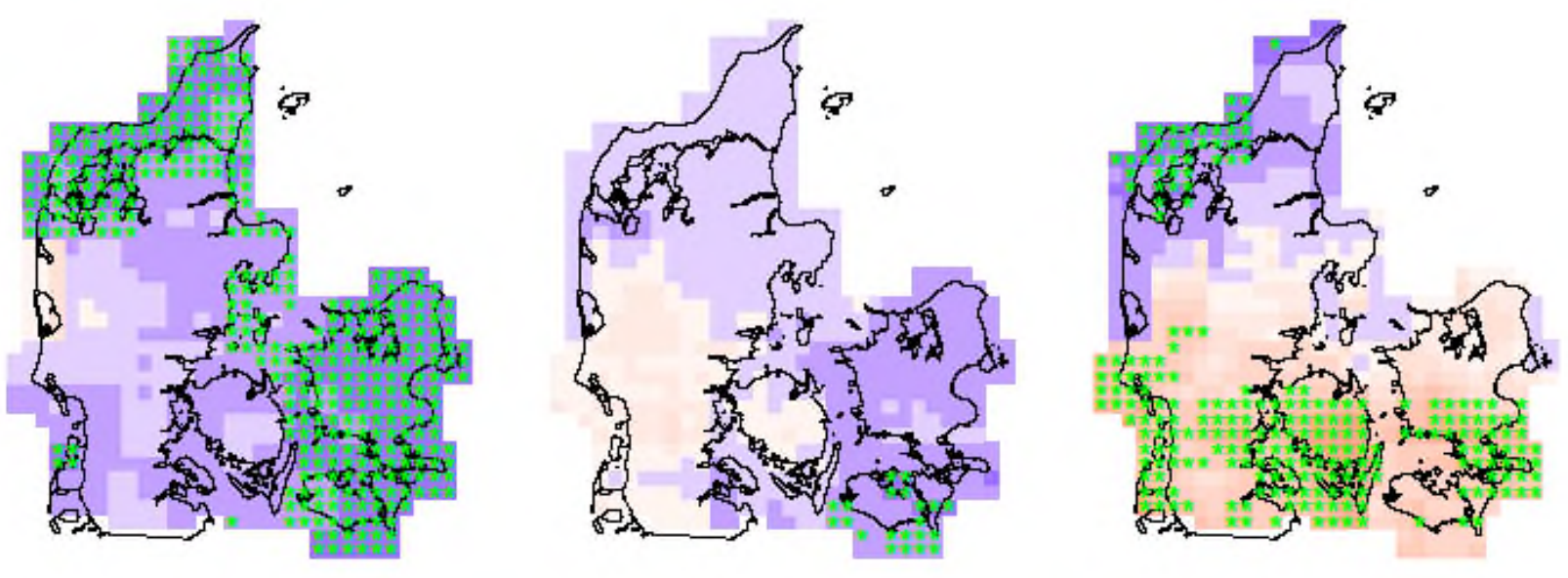

CRPSS

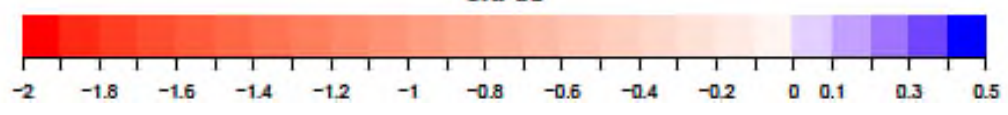


Figure S5: As in Fig. 6, but for autumn. 


\section{Precipitation}
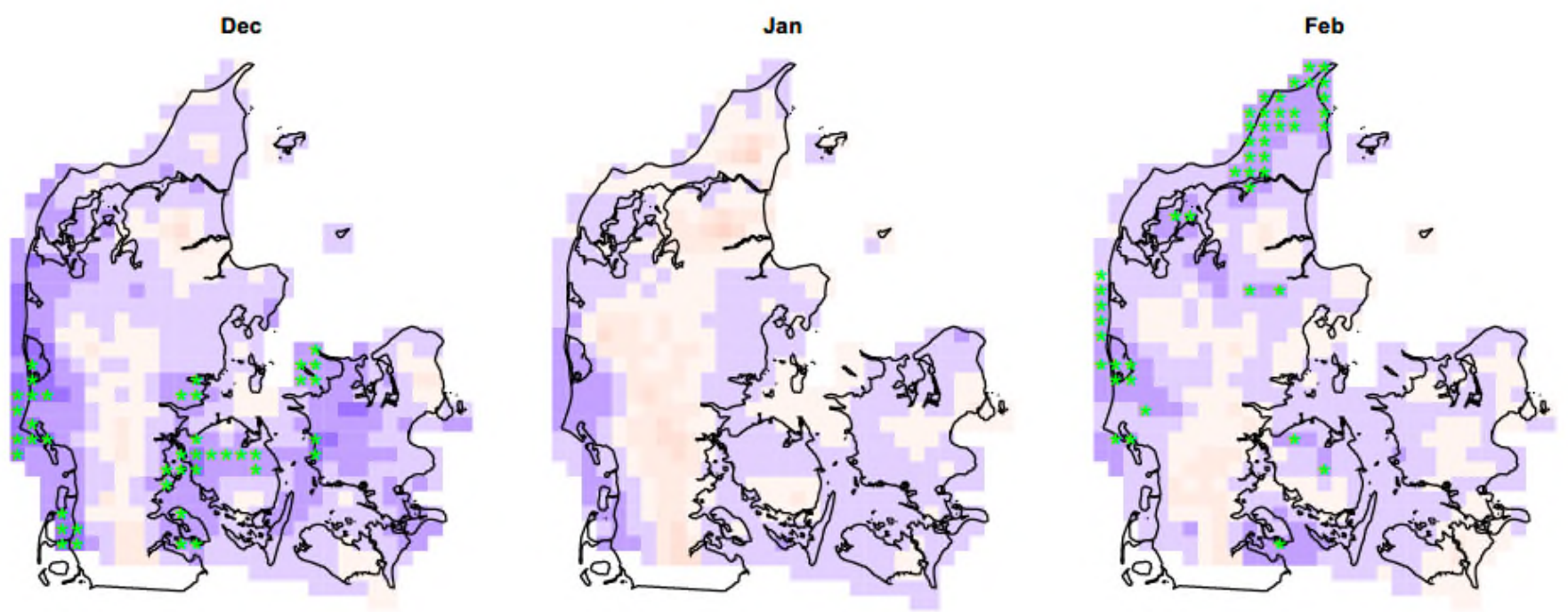

\section{Temperature}
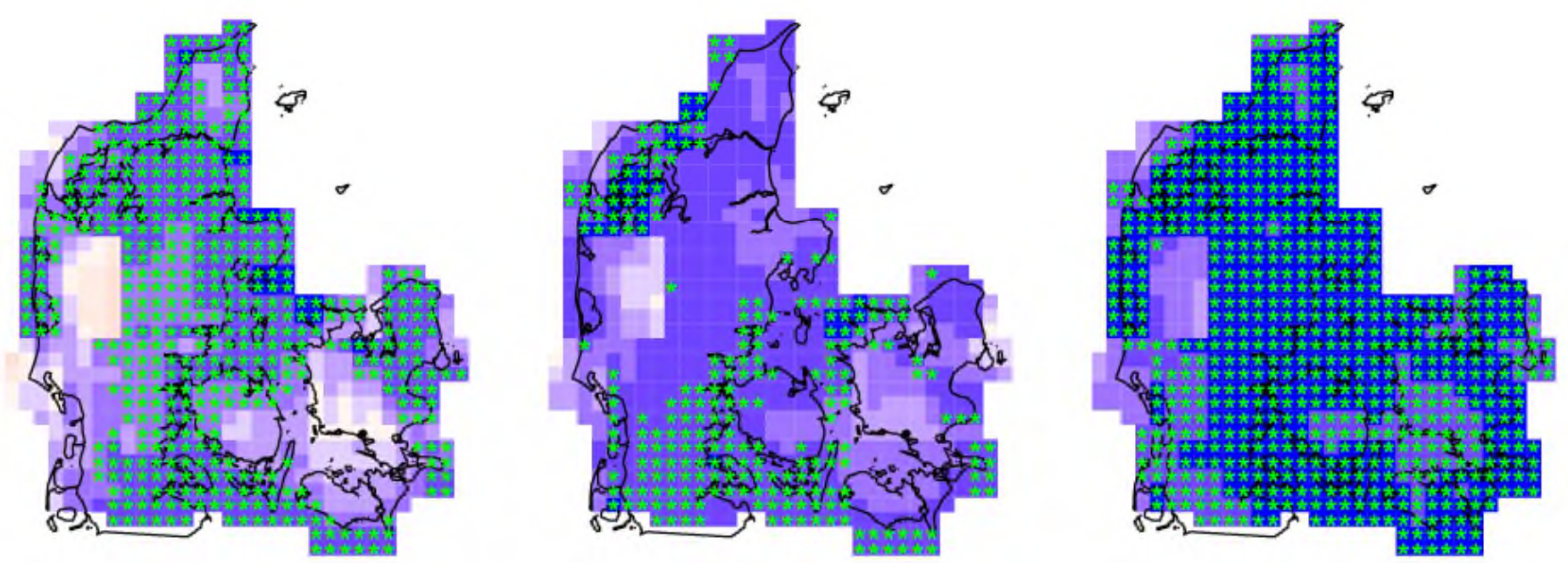

\section{Reference Evapotranspiration}
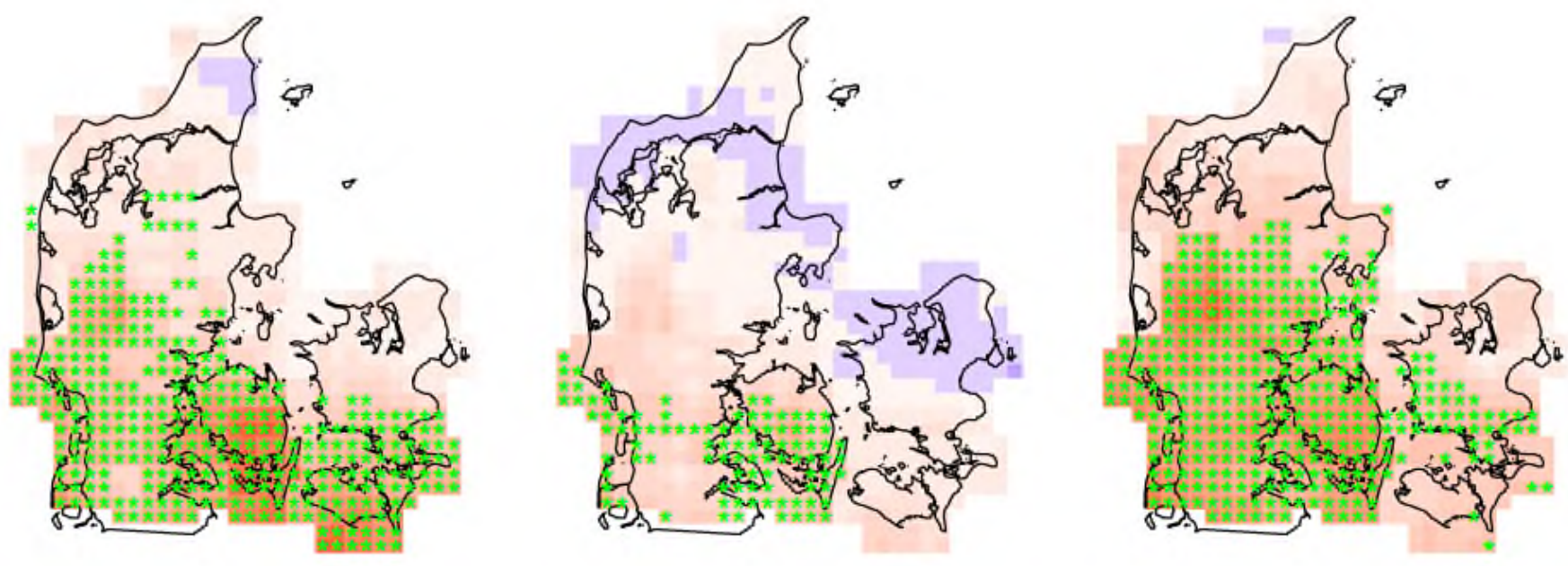
Figure S6: As in Fig. 6, but for winter. 


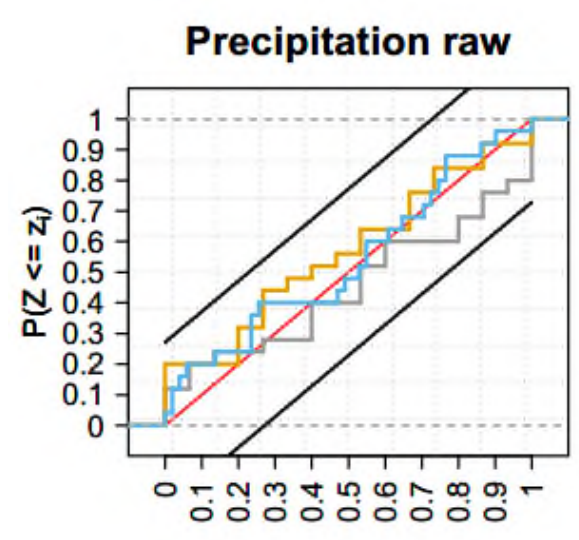

Precipitation LS

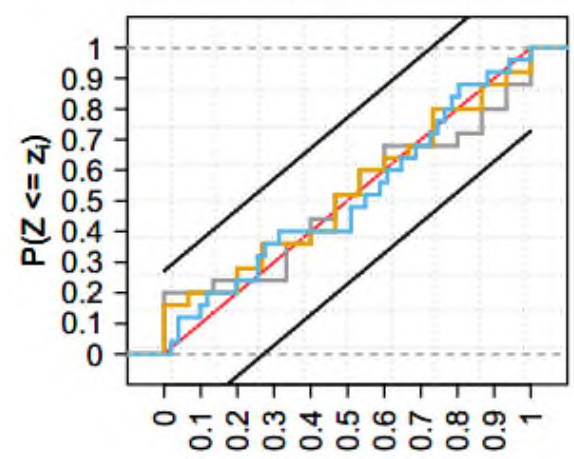

Precipitation QM

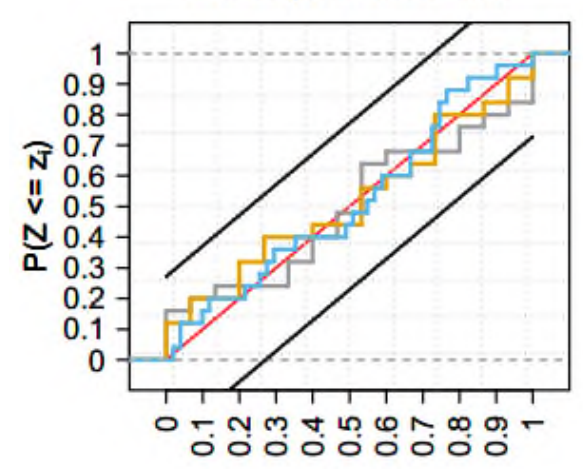

$z_{i}$

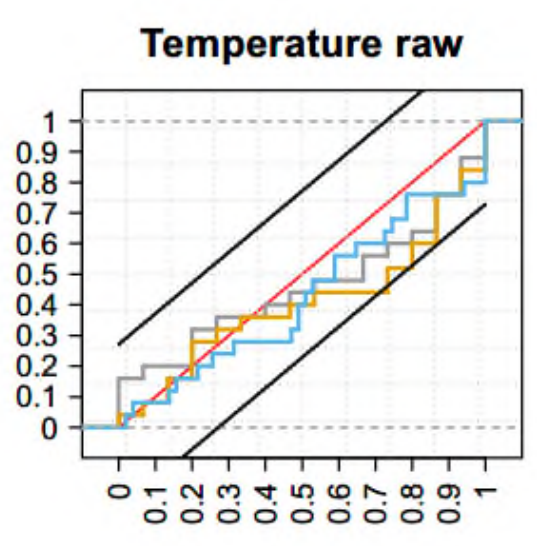

Temperature LS

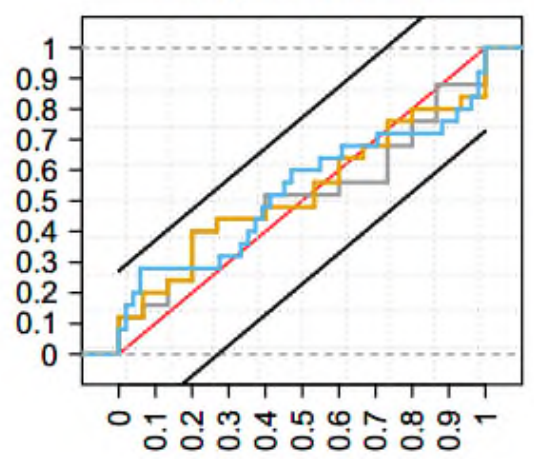

Temperature QM

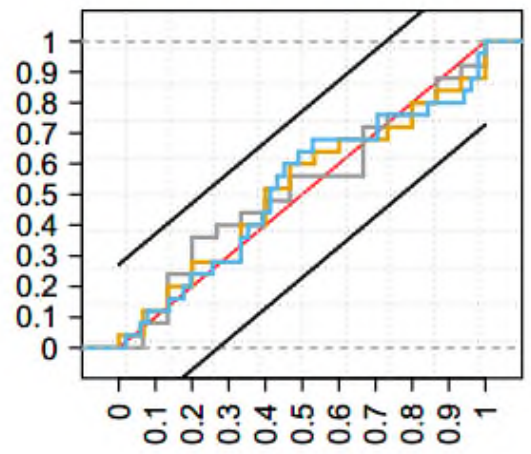

$\mathbf{z}_{\mathrm{i}}$
Reference

Evapotranspiration raw

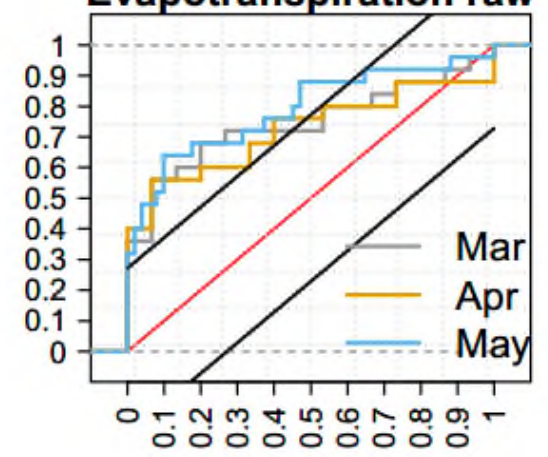

Reference

Evapotranspiration LS

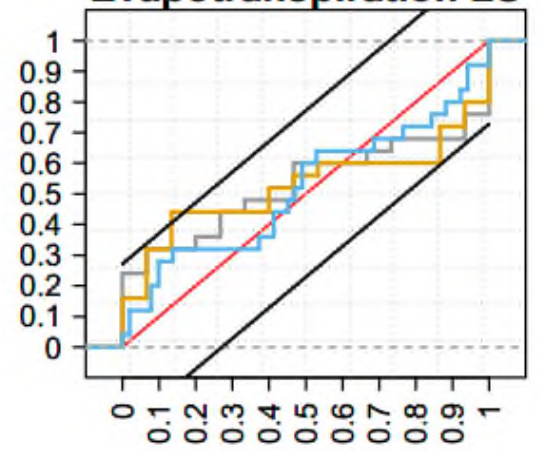

Reference Evapotranspiration QM

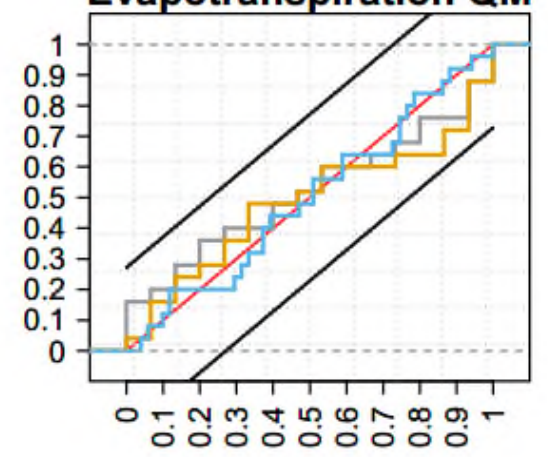

$z_{i}$

Figure S7: As in Fig. 7, but for spring. 

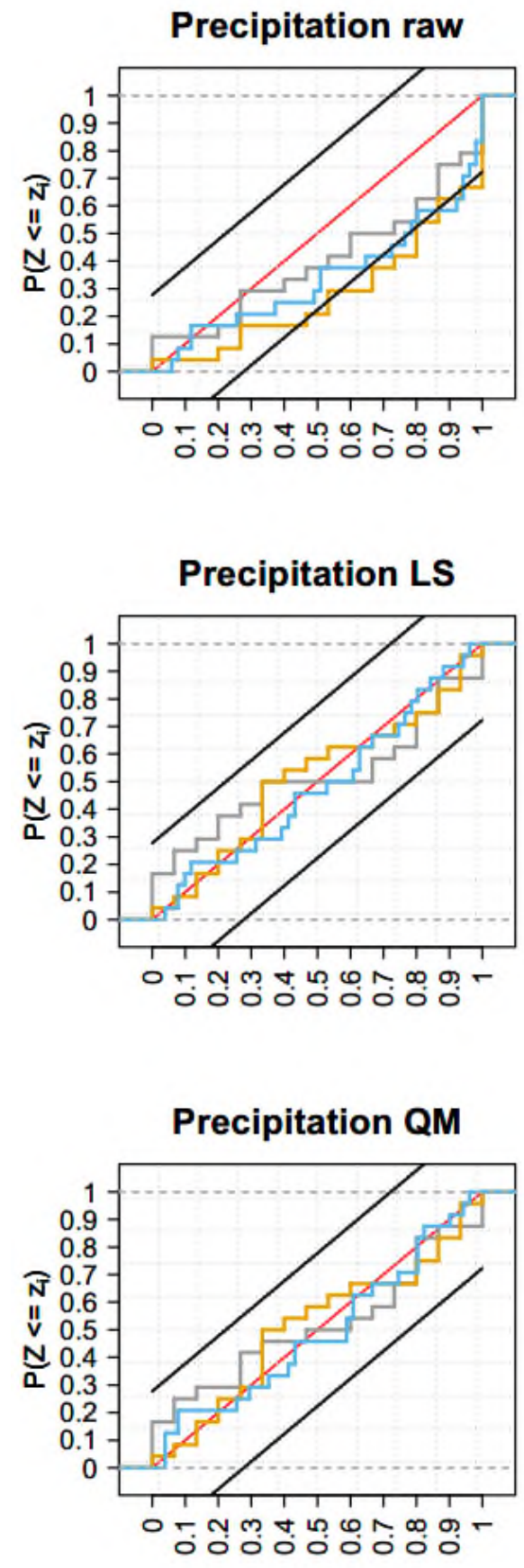

$\mathbf{z}_{\mathbf{i}}$
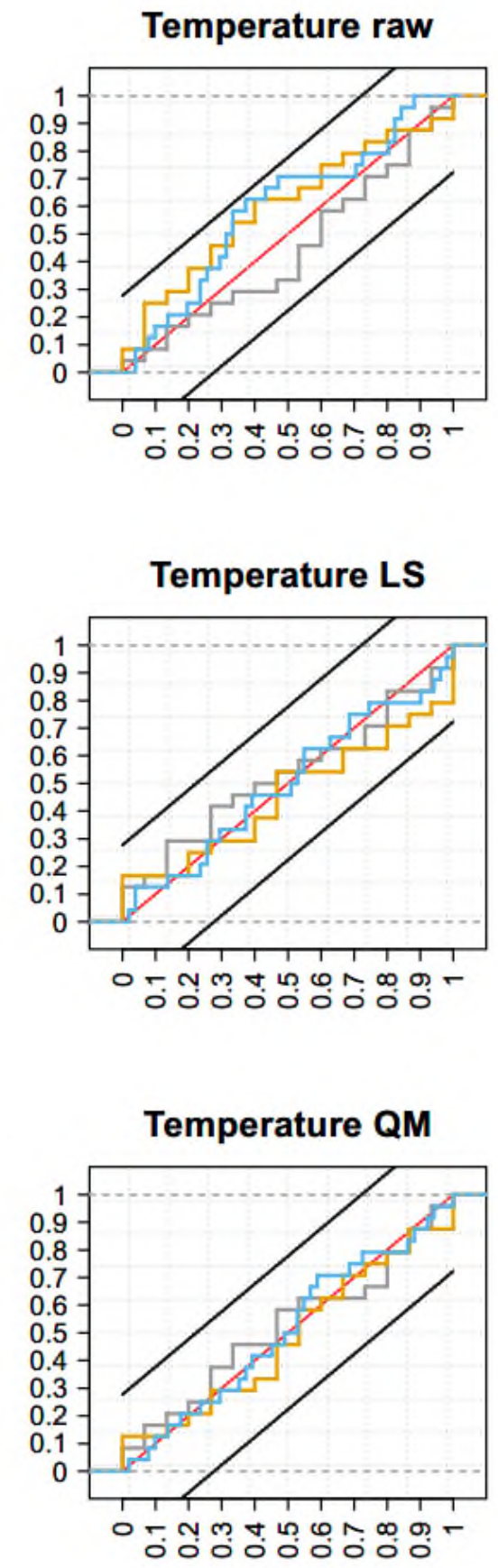

$z_{i}$

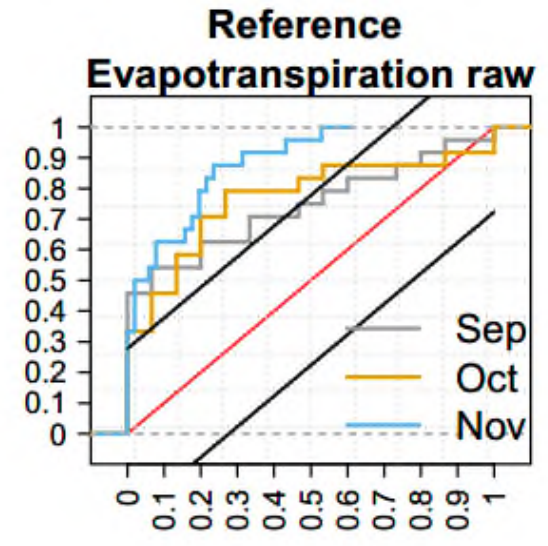

Reference

Evapotranspiration LS

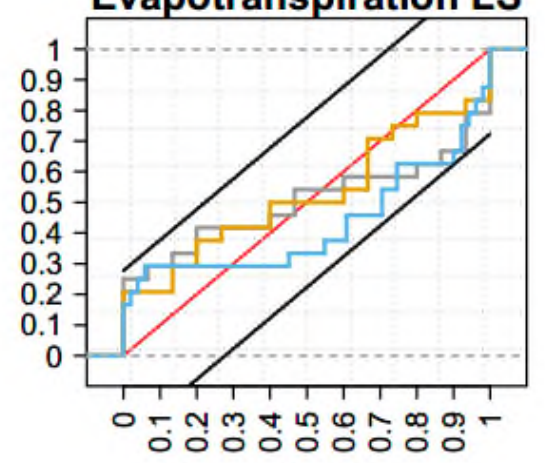

Reference

Evapotranspiration QM

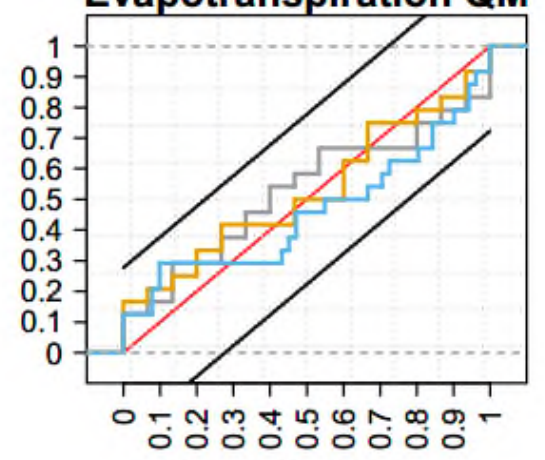

$\mathbf{z}_{\mathrm{i}}$ 


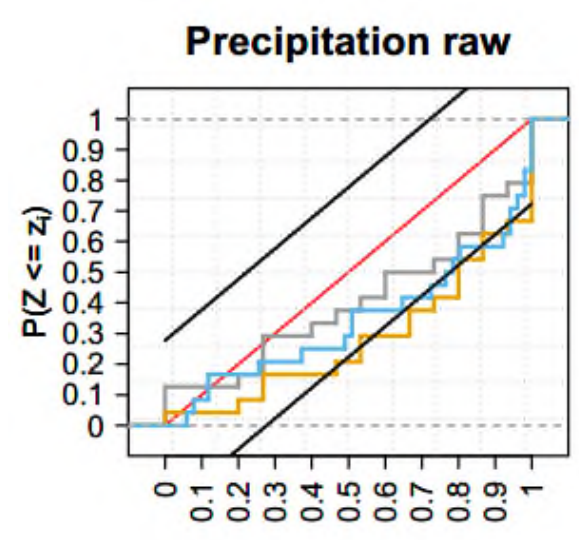

Precipitation LS

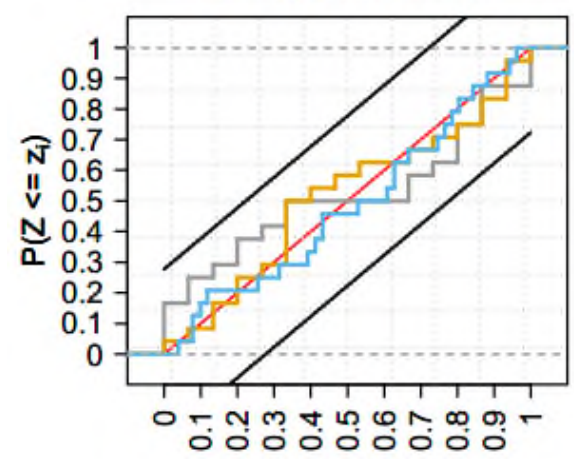

Precipitation QM

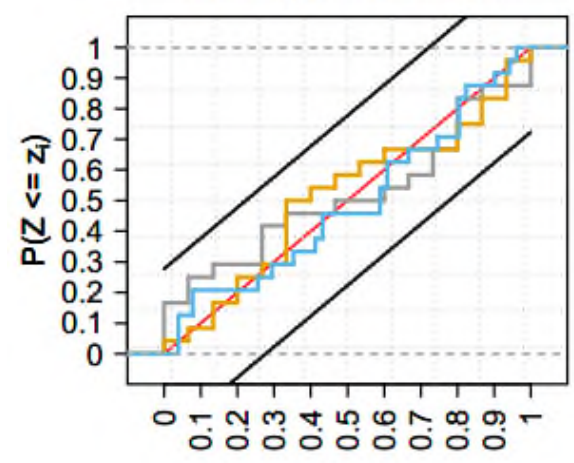

$\mathbf{z}_{\mathbf{i}}$

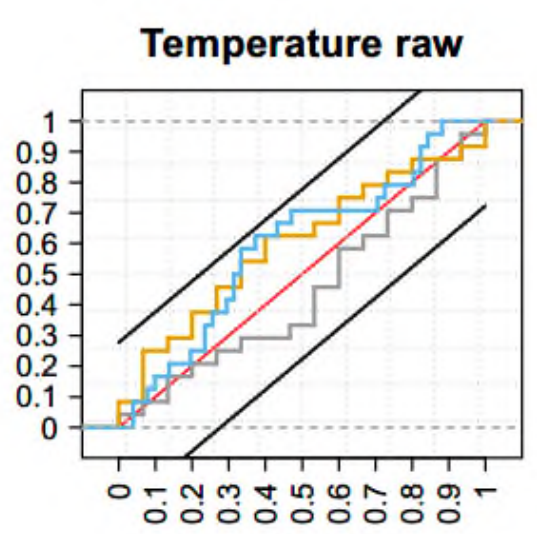

Temperature LS

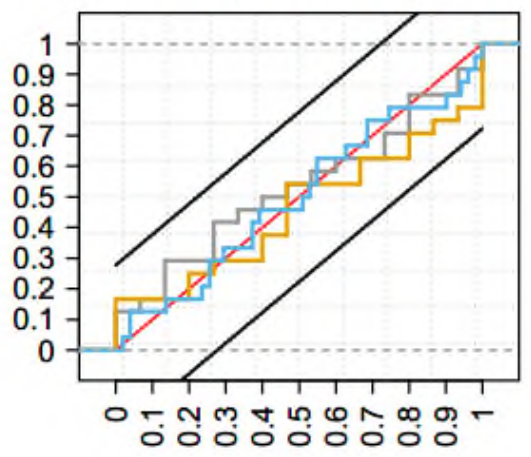

Temperature QM

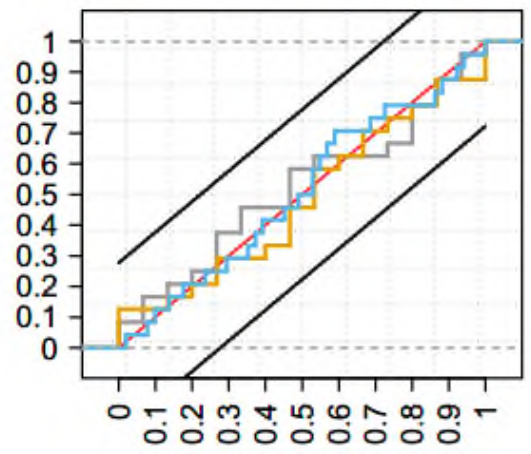

$\mathbf{z}_{\mathbf{i}}$
Reference

Evapotranspiration raw

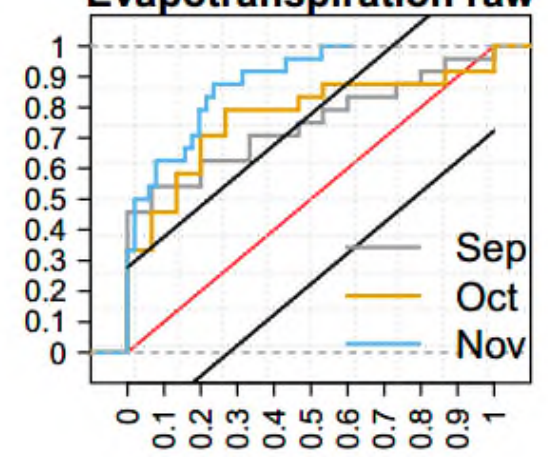

Reference

Evapotranspiration LS

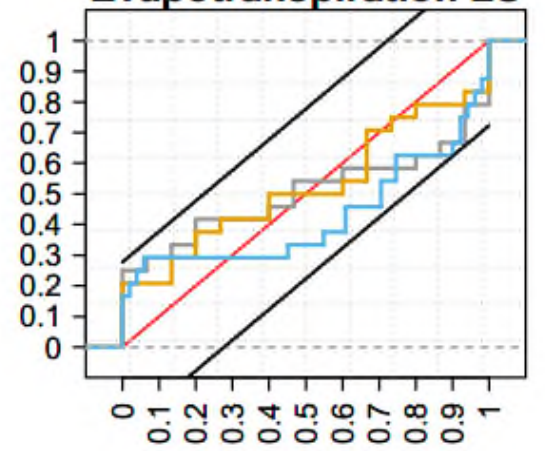

Reference Evapotranspiration QM

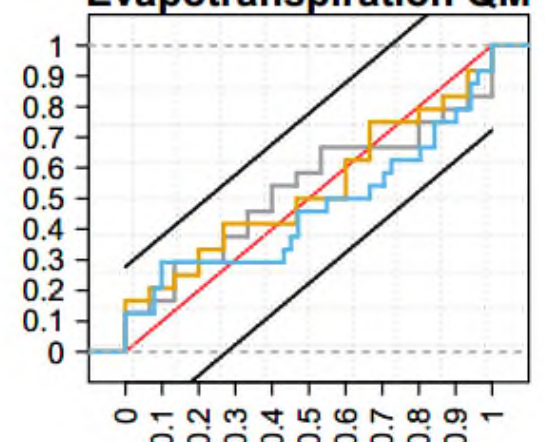

$z_{i}$

Figure S8: As in Fig. 7, but for autumn. 

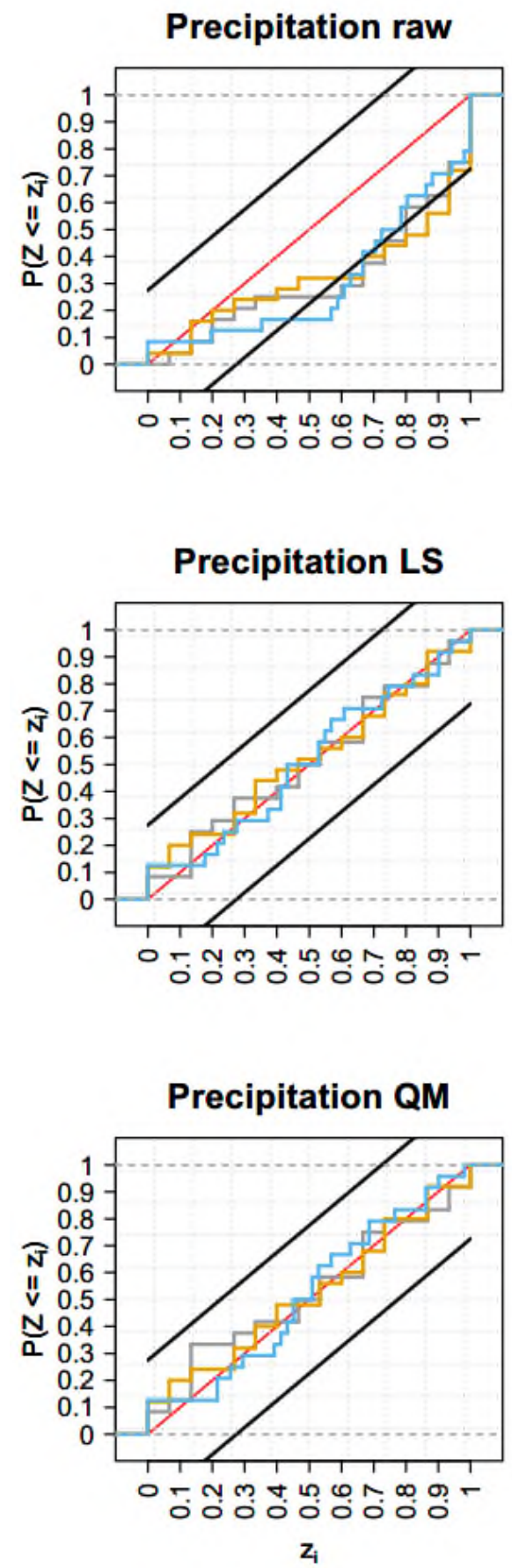

Figure S9: As in Fig. 7, but for winter.
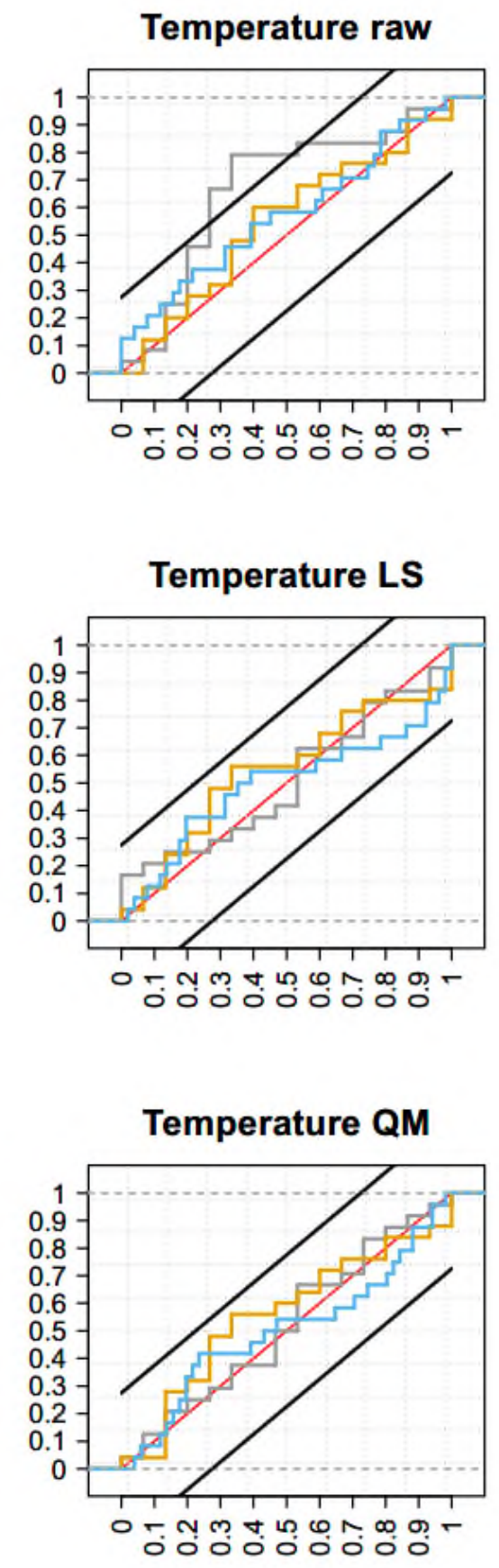

$\mathbf{z}_{\mathrm{i}}$

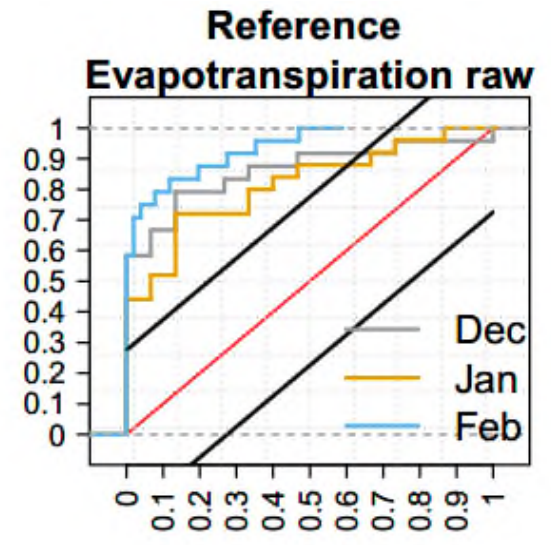

Reference

Evapotranspiration LS

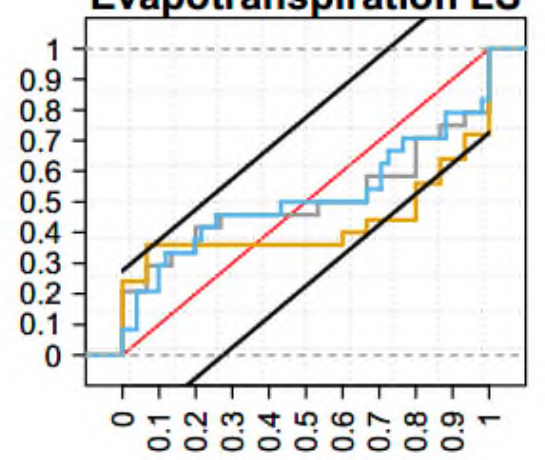

Reference

Evapotranspiration QM

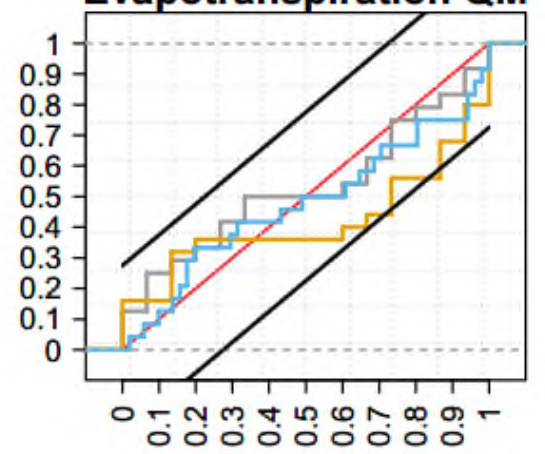

$\mathbf{z}_{\mathrm{i}}$ 

Precipitation RAW

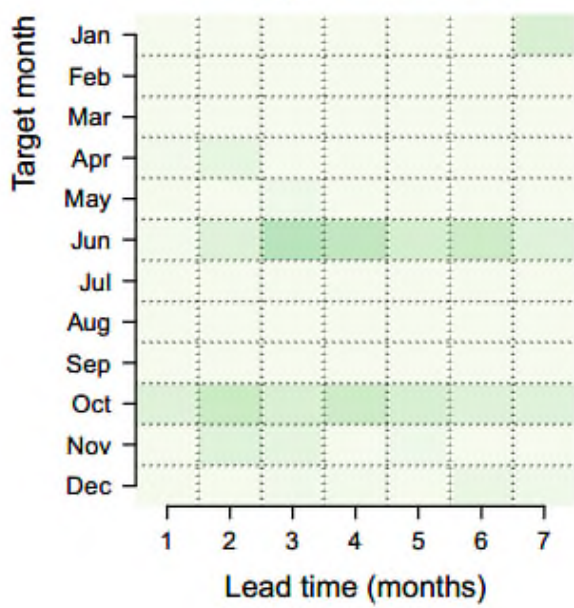

Precipitation LS

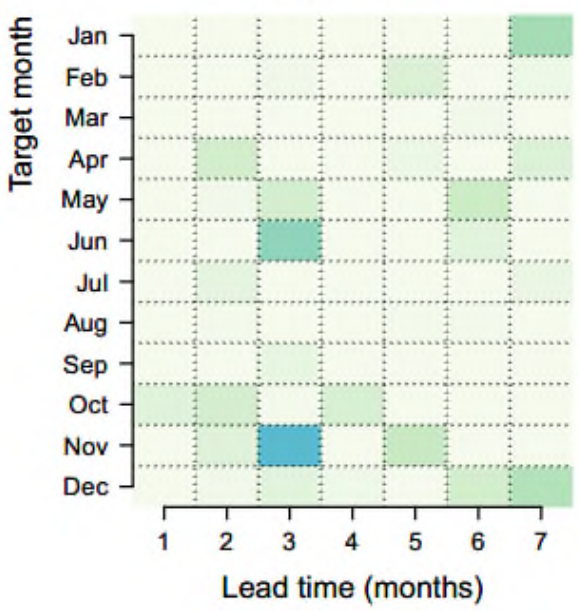

Precipitation QM

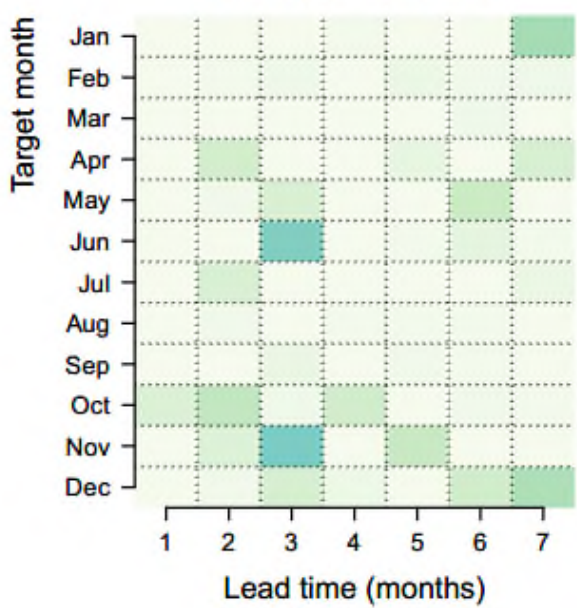

Temperature RAW

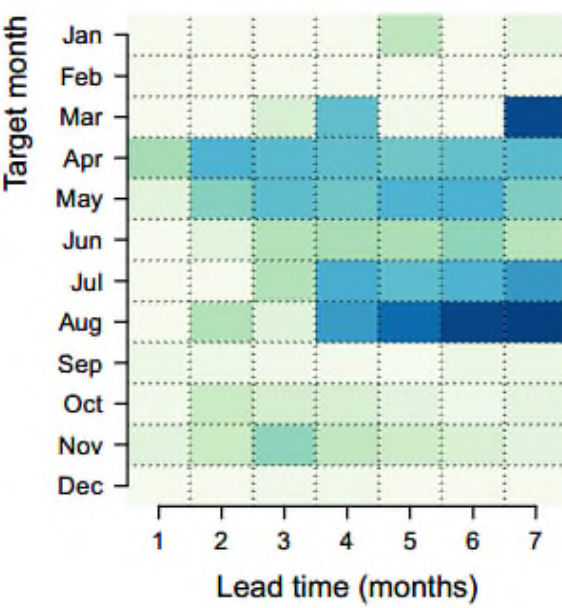

Temperature LS

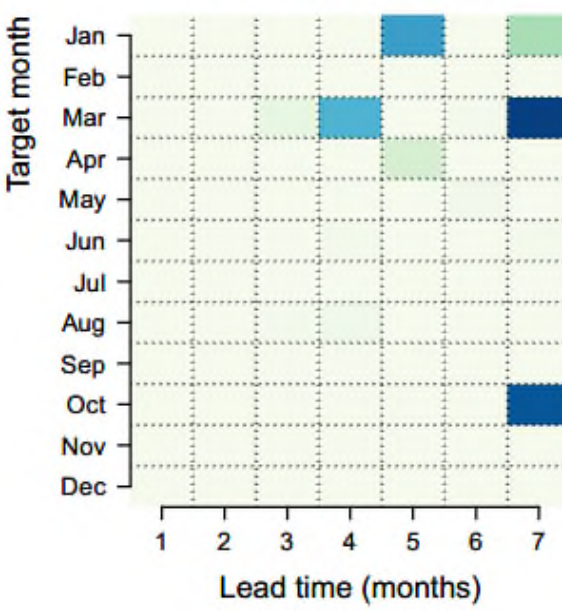

Temperature QM

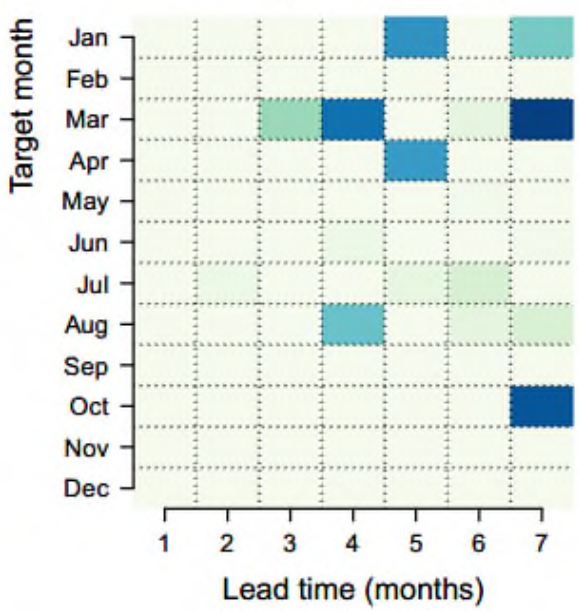

$\%$
Reference

Evapotranspiration RAW

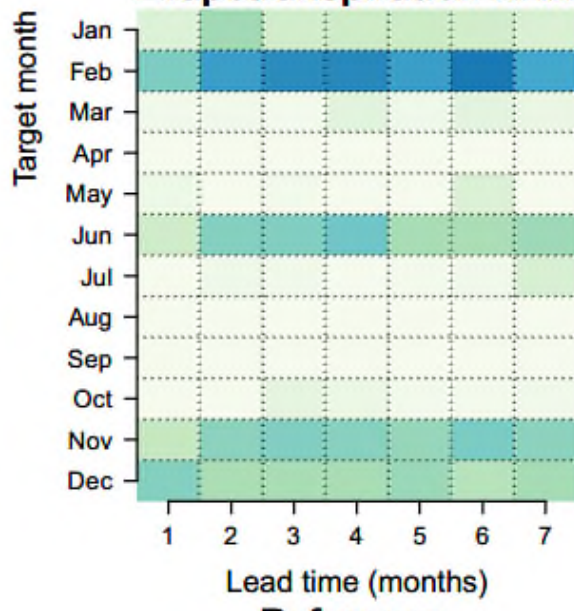

Reference

Evapotranspiration LS

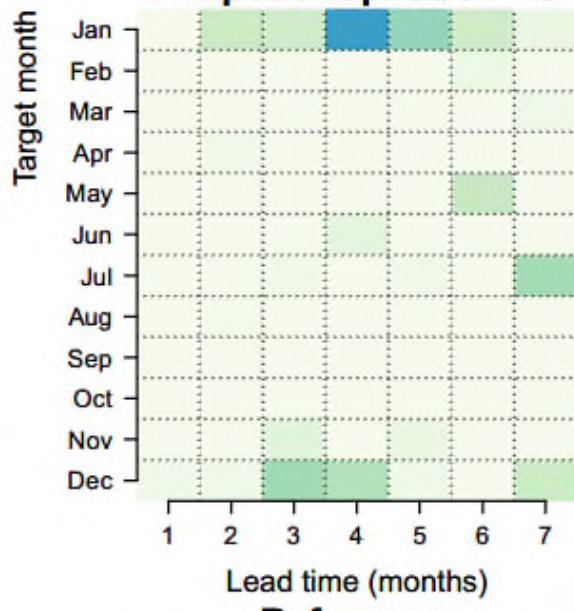

Reference

Evapotranspiration QM

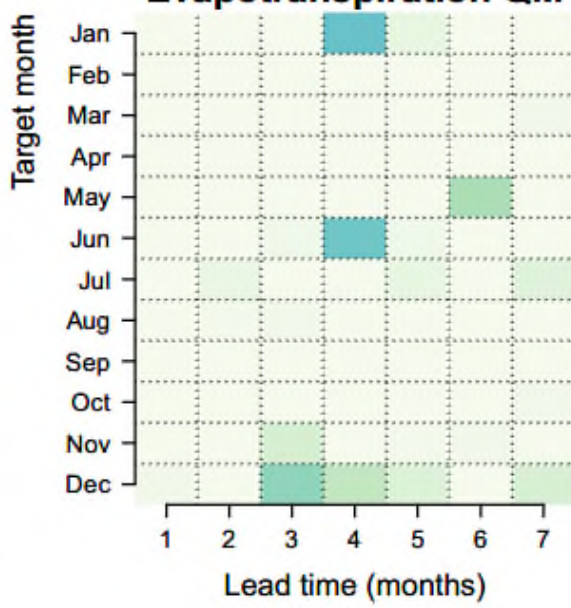

\begin{tabular}{|c|c|c|c|c|c|c|c|c|}
\hline$T$ & $T$ & $T$ & $T$ & 1 & 1 & $T$ & $T$ & \\
\hline 10 & 20 & 30 & 40 & 50 & 60 & 70 & 80 & 10 \\
\hline
\end{tabular}

Figure S10: As in Fig. 9, but for negative accuracy (CRPSS in Eq. (8)). 


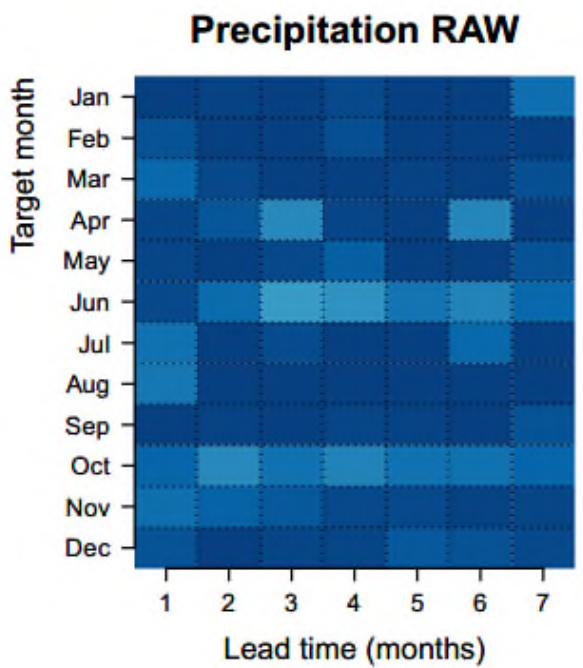

Precipitation LS

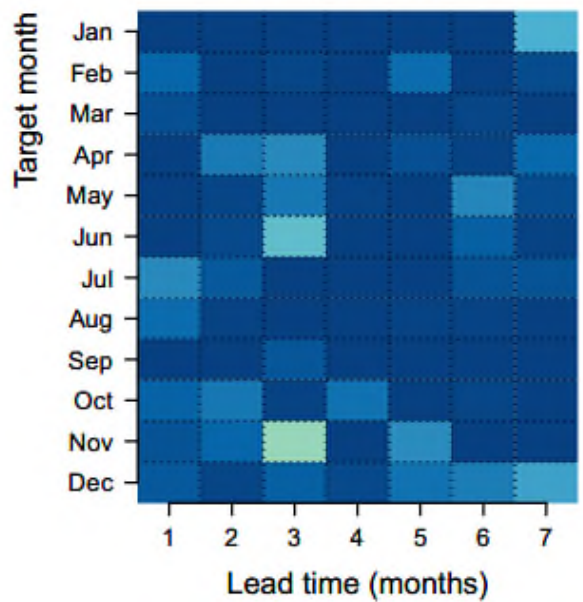

Precipitation QM

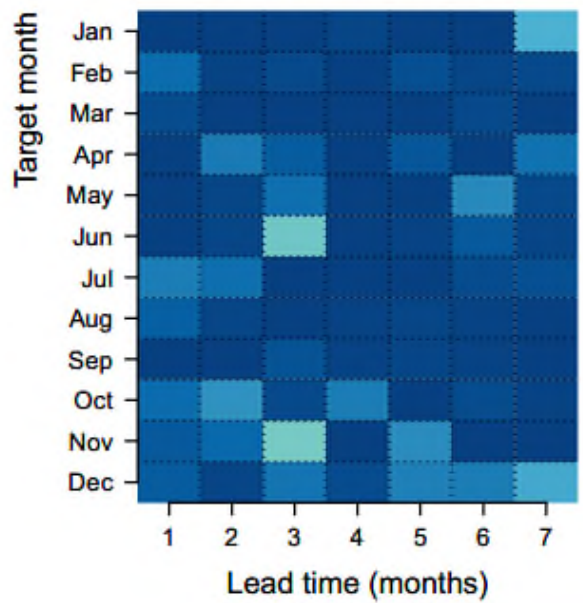

Temperature RAW

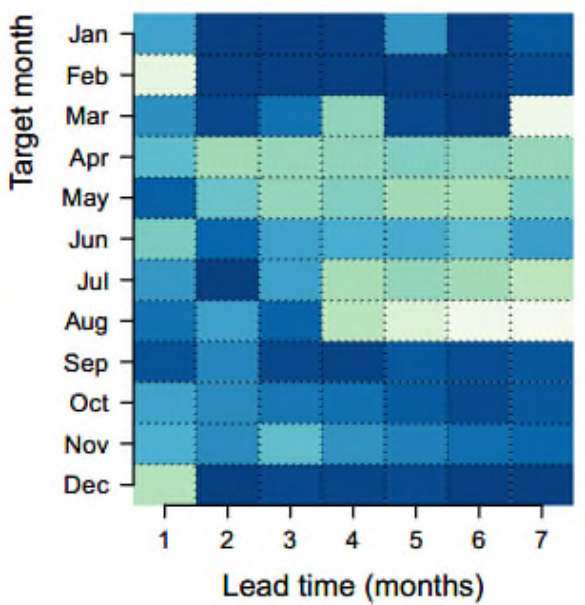

Temperature LS

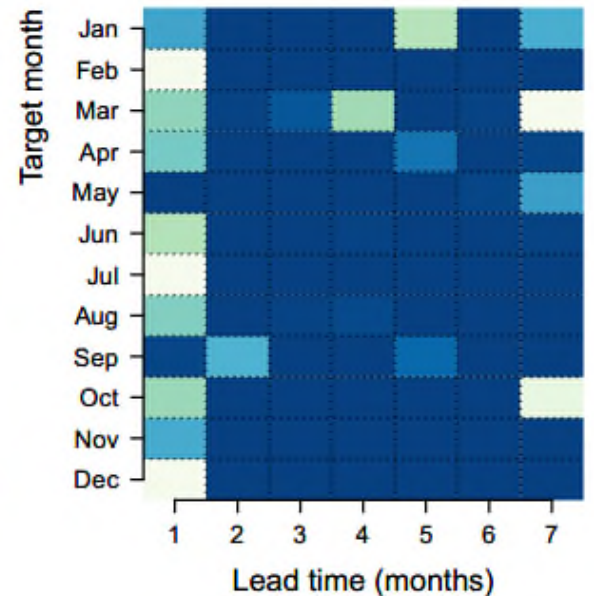

Temperature QM

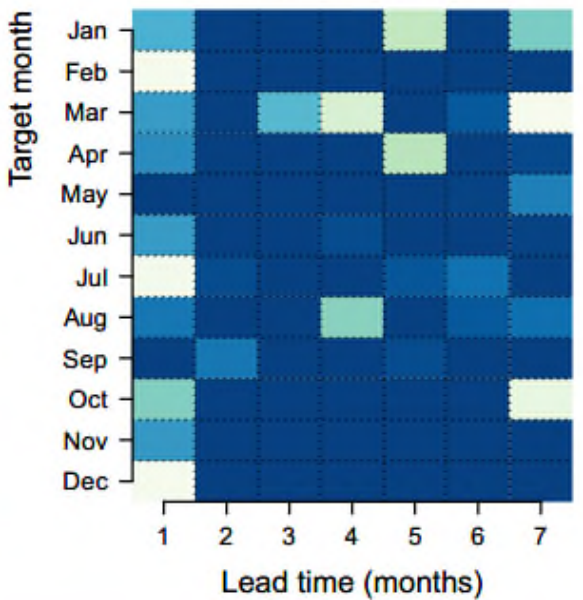

$\%$

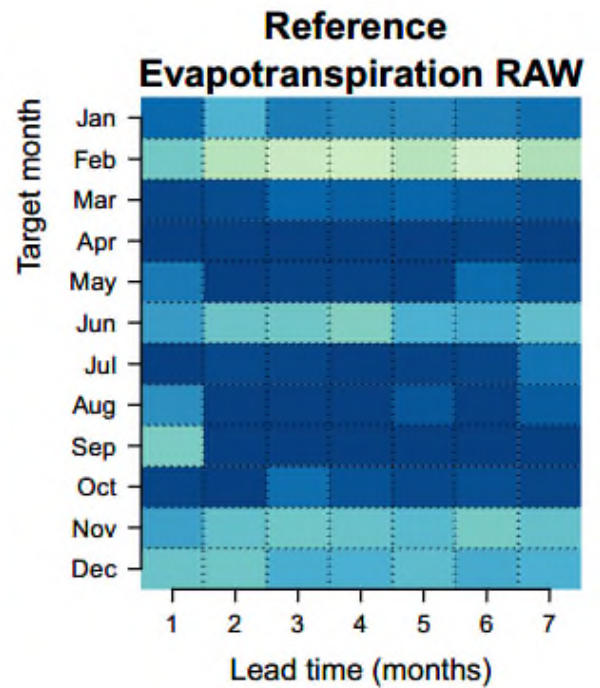

Reference

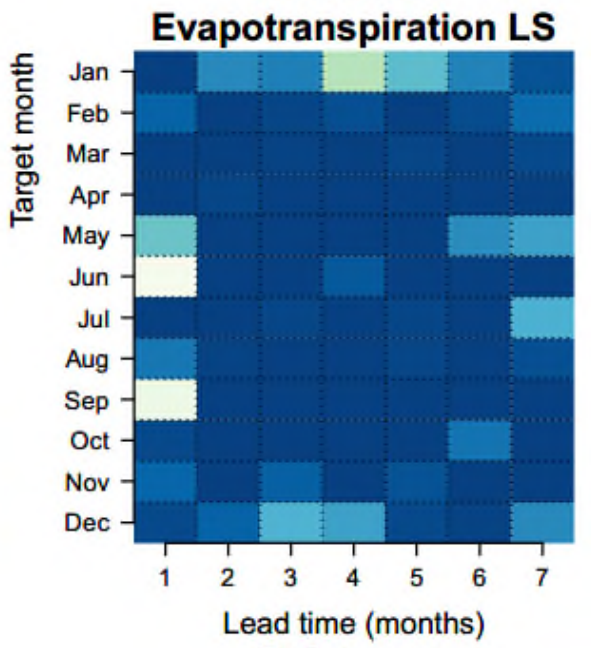

Reference

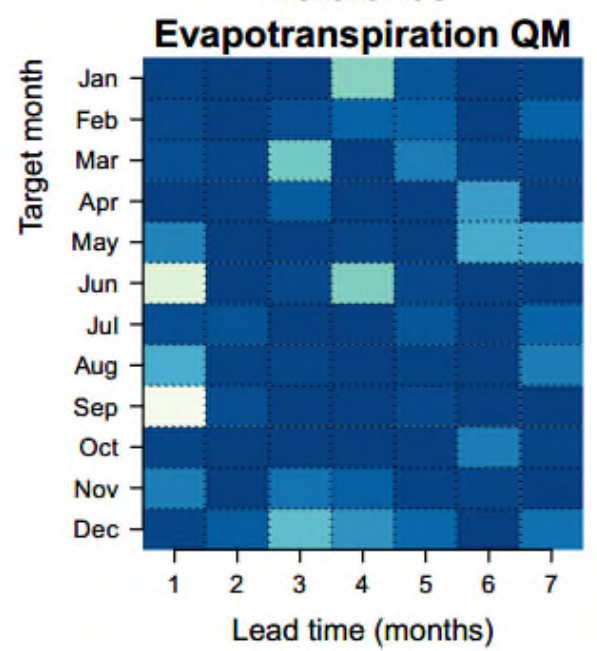

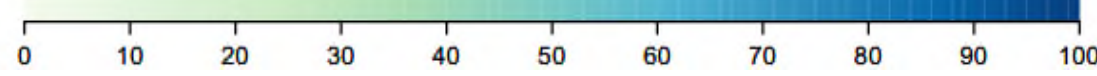




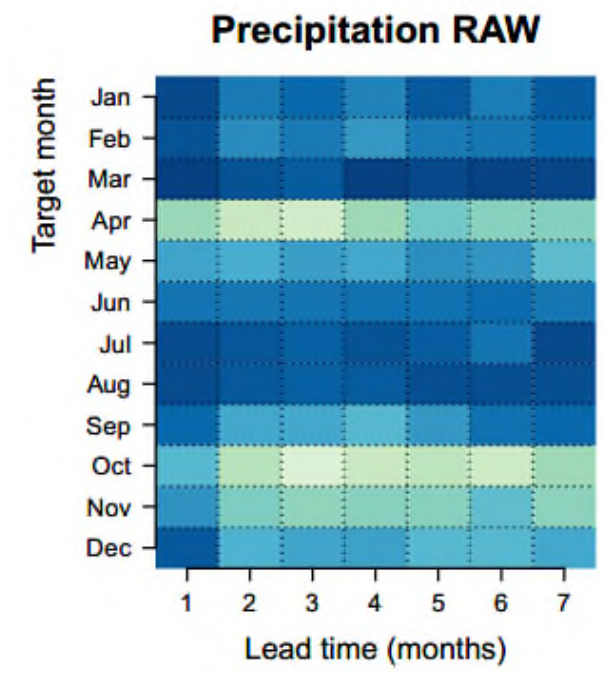

Precipitation LS

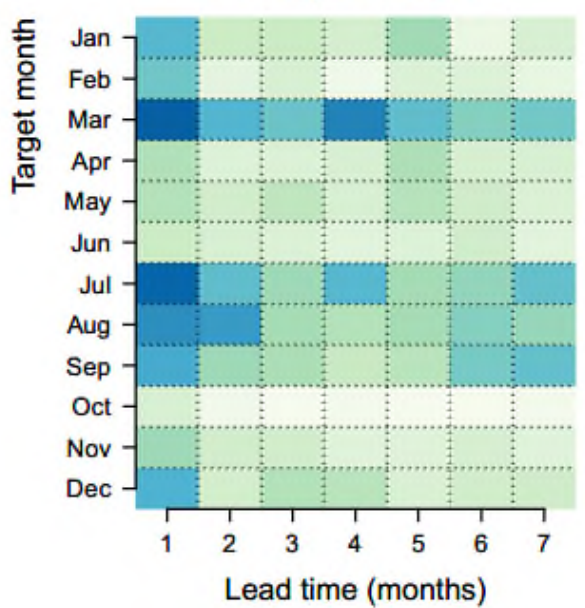

Precipitation QM

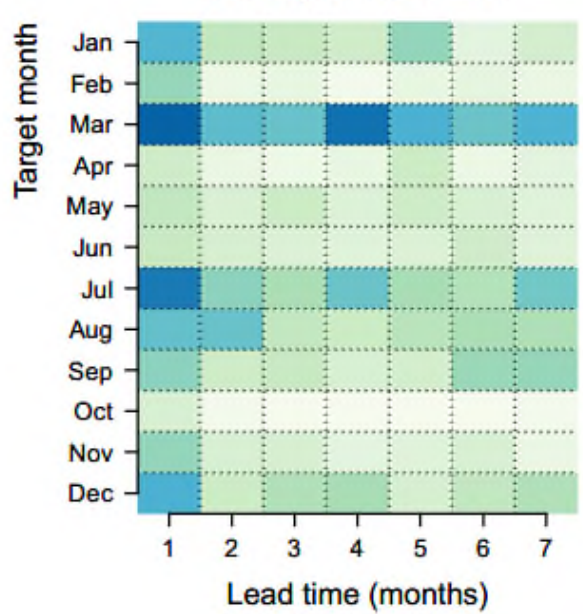

Temperature RAW

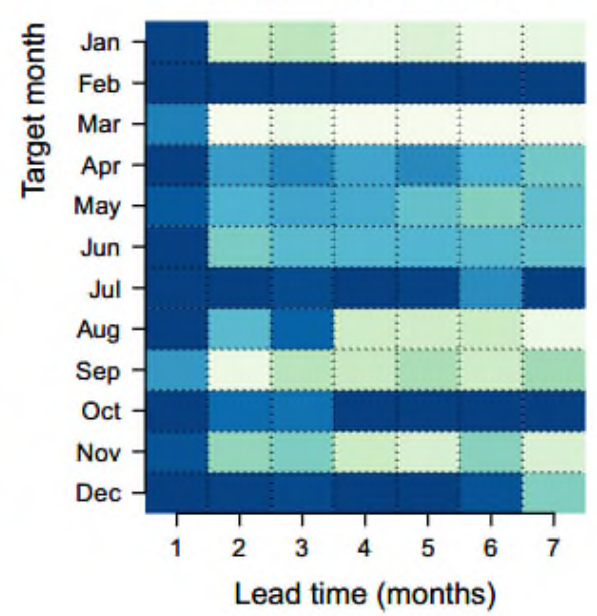

Temperature LS

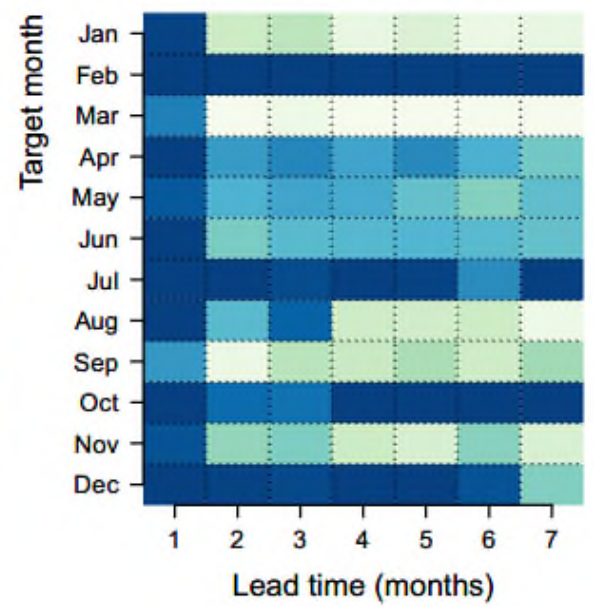

Temperature QM

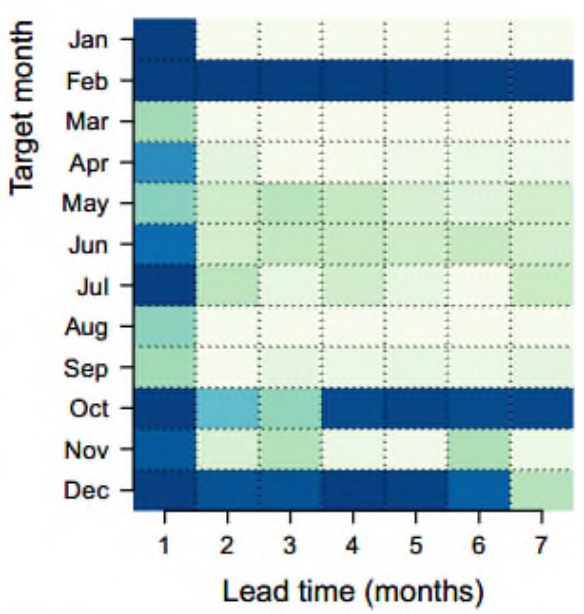

Reference

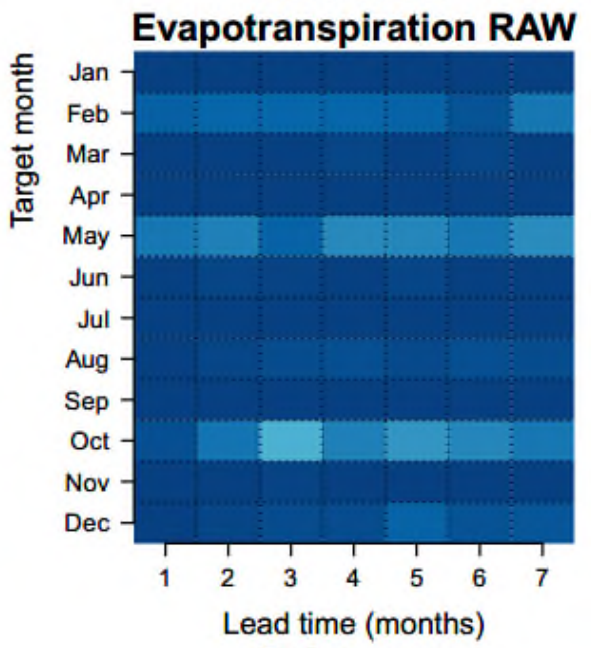

Reference

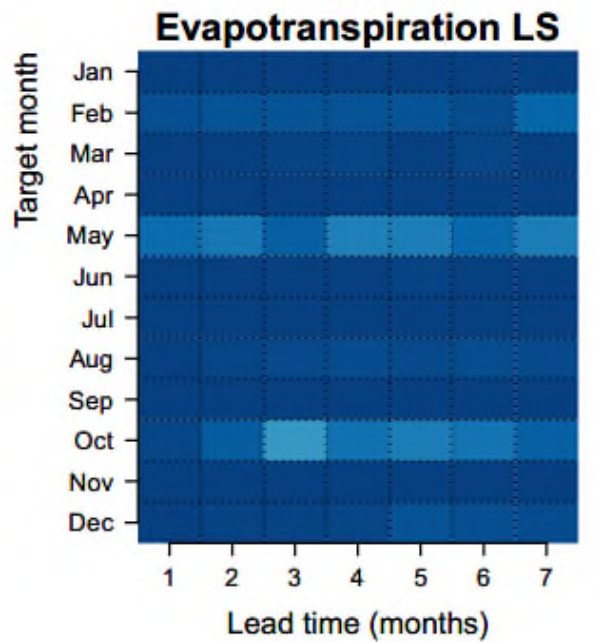

Reference

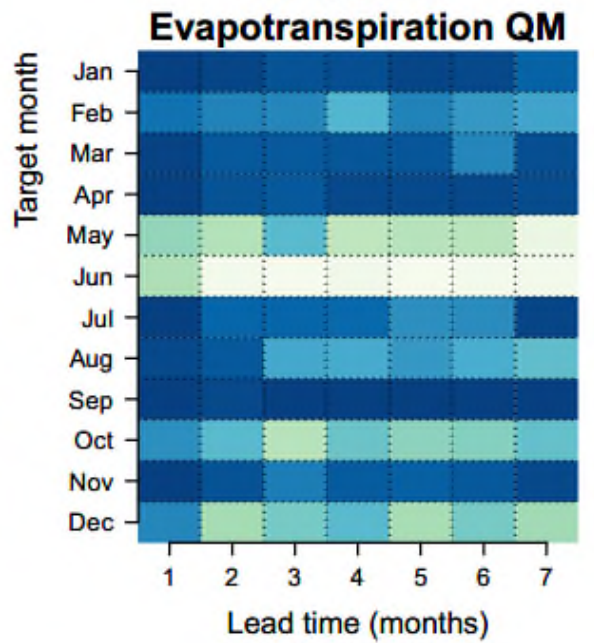

$\%$

\begin{tabular}{|c|c|c|c|c|c|c|c|c|c|}
\hline 「 & $T$ & $T$ & $T$ & $T$ & $T$ & $T$ & $T$ & $T$ & $T$ \\
\hline 0 & 10 & 20 & 30 & 40 & 50 & 60 & 70 & 80 & 90 \\
\hline
\end{tabular}




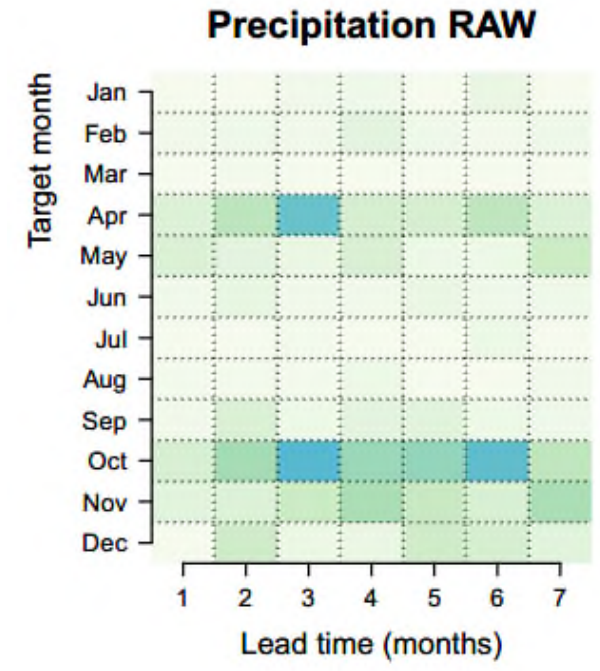

Precipitation LS

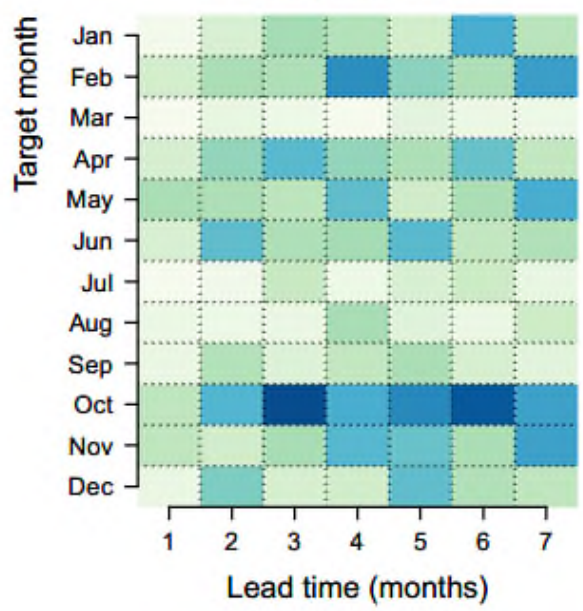

Precipitation QM

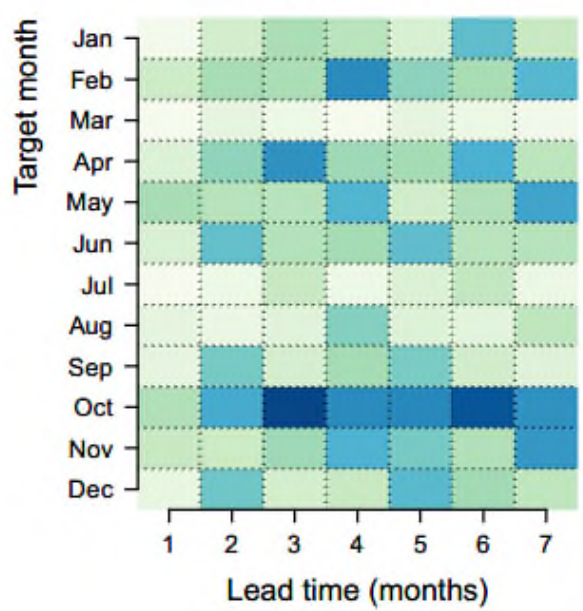

Temperature RAW

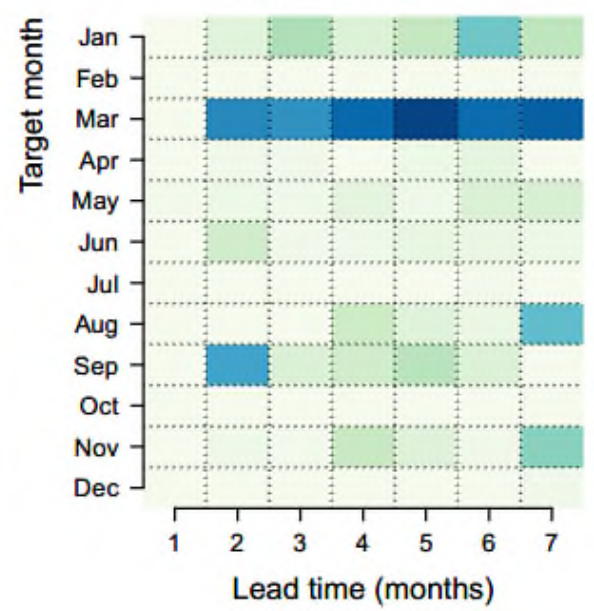

Temperature LS

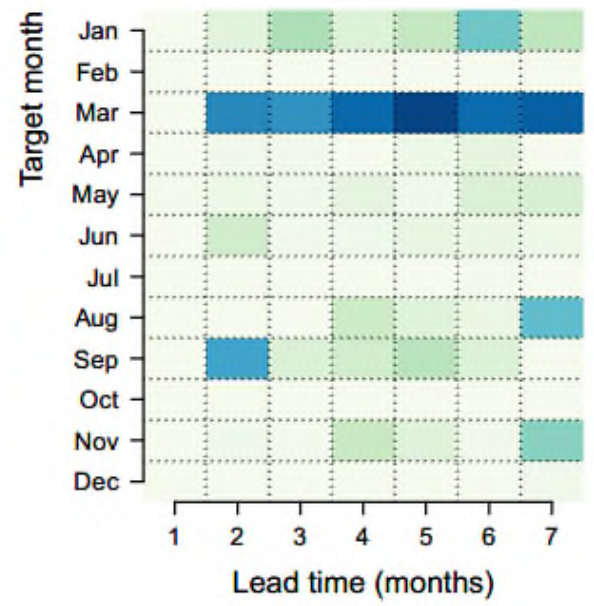

Temperature QM

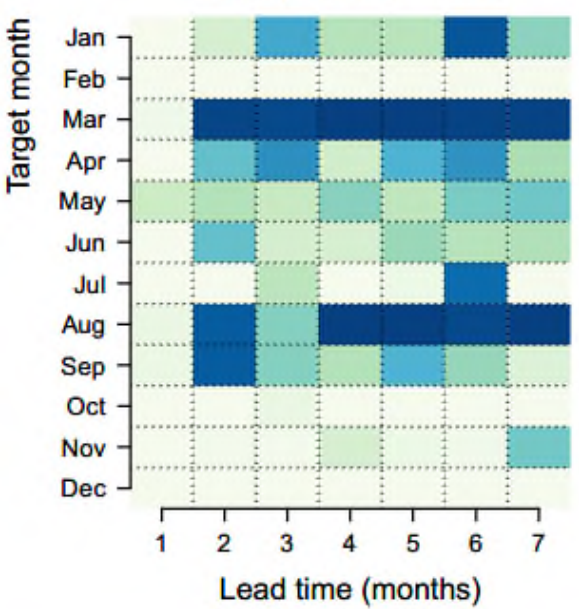

Reference

Evapotranspiration RAW

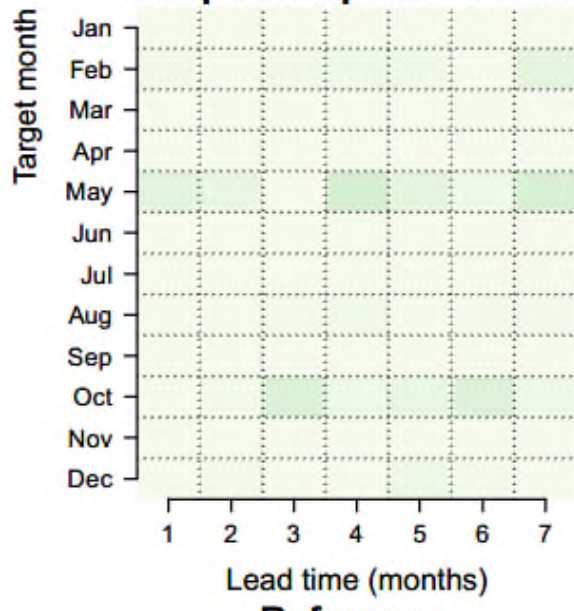

Reference

Evapotranspiration LS

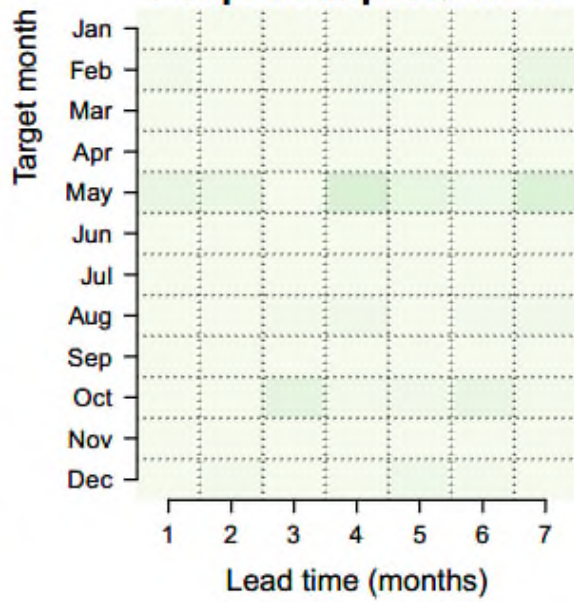

Reference

Evapotranspiration QM

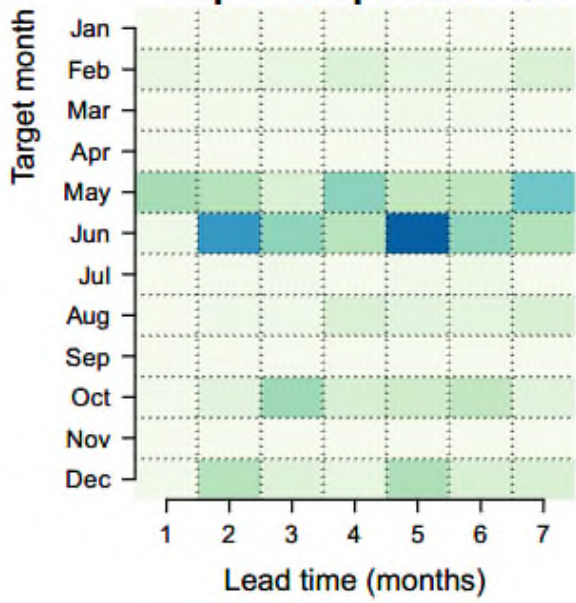
$\%$

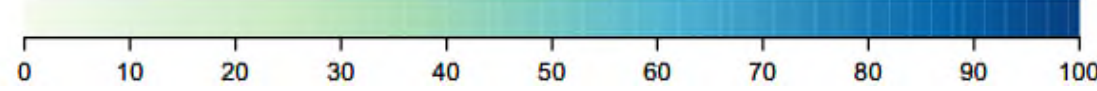




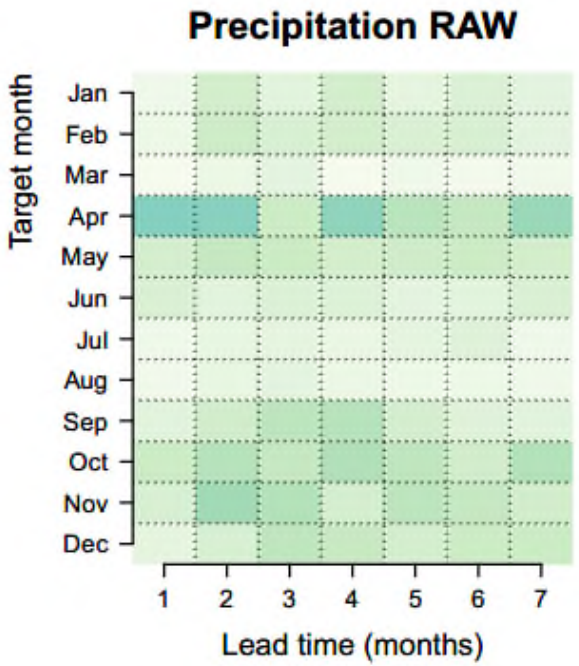

Precipitation LS

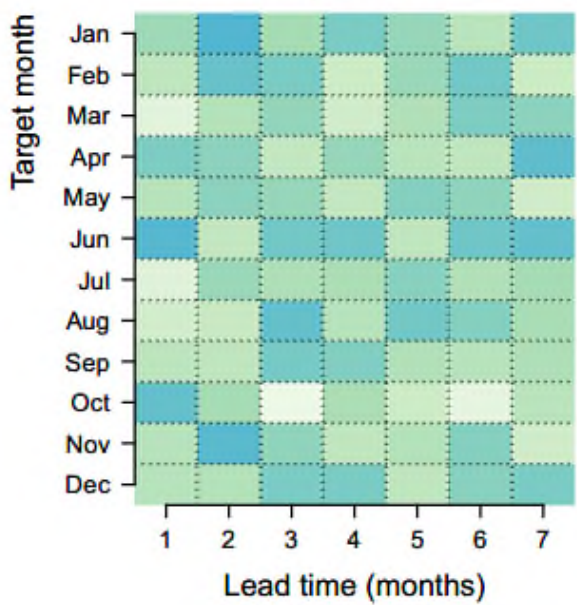

Precipitation QM

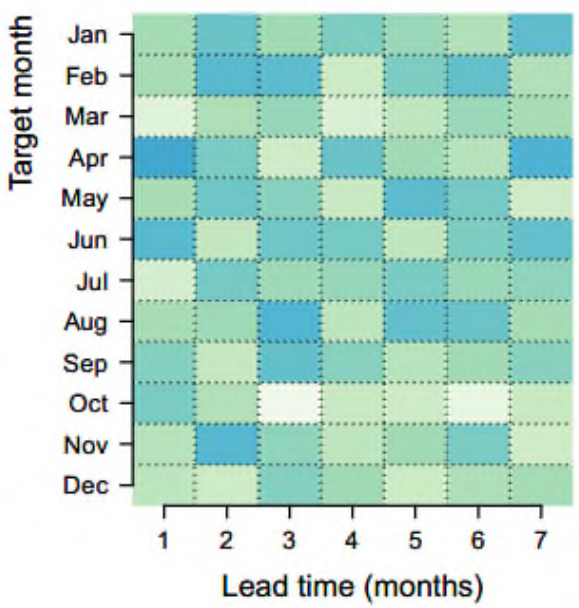

Temperature RAW

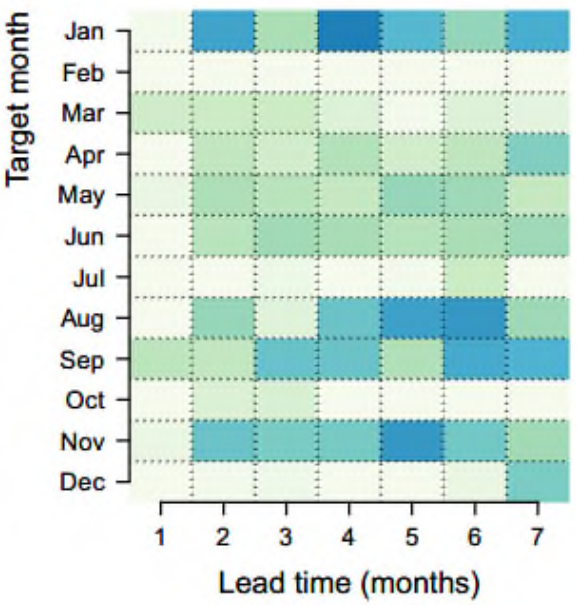

Temperature LS

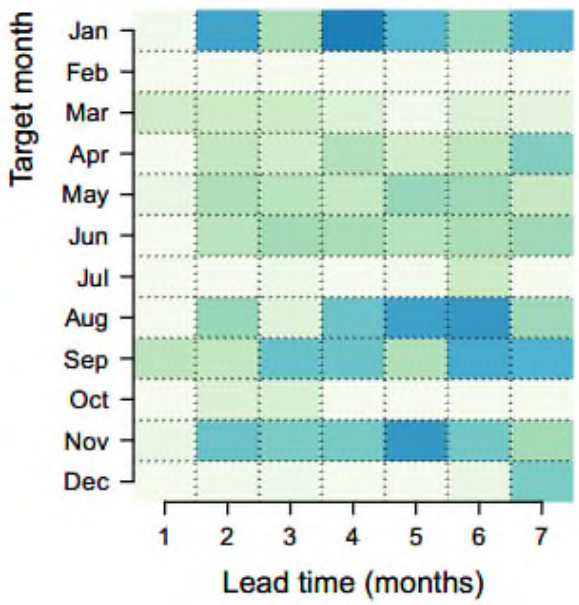

Temperature QM

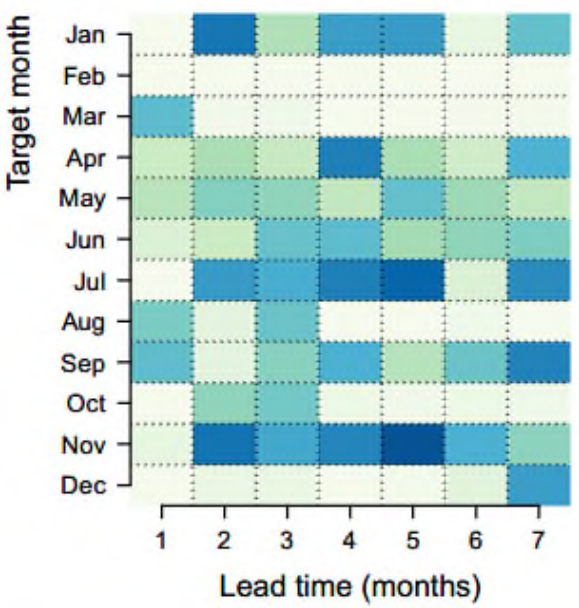

$\%$
Reference

Evapotranspiration RAW

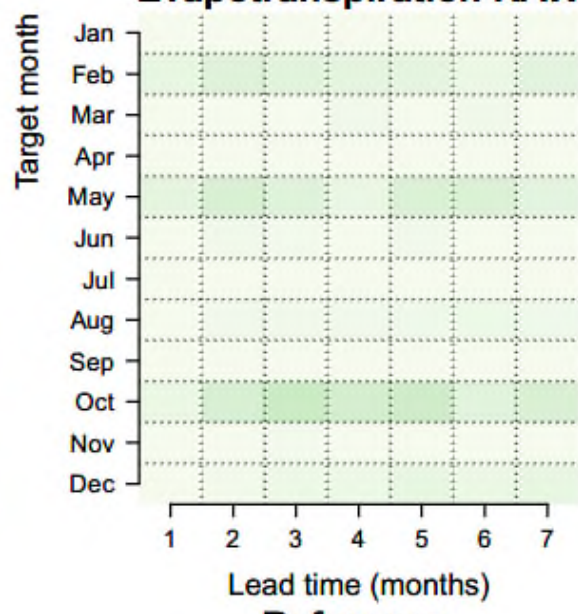

Reference

Evapotranspiration LS

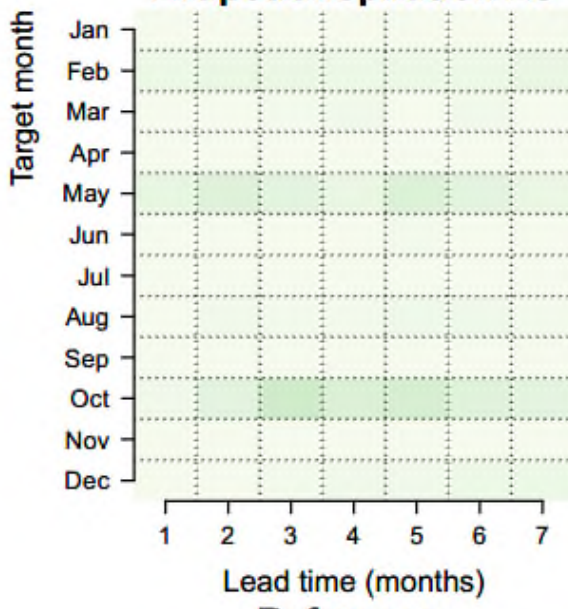

Reference

Evapotranspiration QM

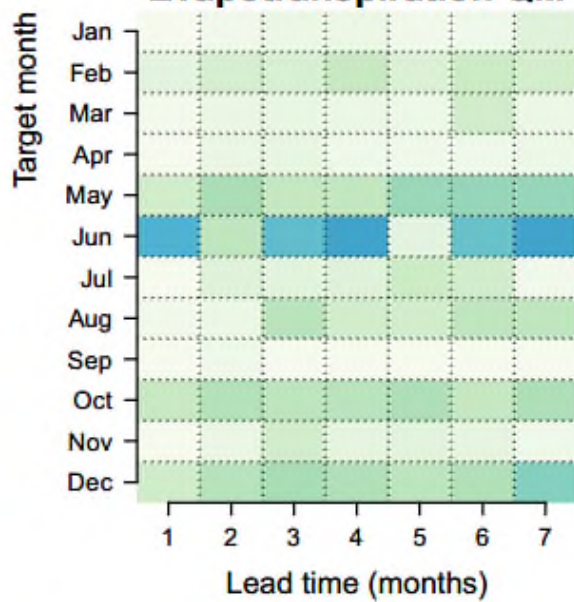

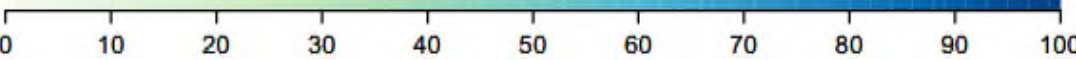

Figure S14: As in Fig. 9, but for equal sharpness (SS in Eq. (8)). 